\title{
Dynamics and thermodynamics of magma mixing: Insights from a simple exploratory model
}

\author{
Frank J. SPERA ${ }^{1, *}$, JASOn S. SChMidT ${ }^{1}$, Wendy A. BOHRSON ${ }^{2}$, AND GUY A. BROWN ${ }^{3}$ \\ ${ }^{1}$ Department of Earth Science, University of California, Santa Barbara, California 93106, U.S.A. \\ ${ }^{2}$ Department of Geological Sciences, Central Washington University, Ellensburg, Washington 98926, U.S.A. \\ ${ }^{3}$ Rocking Hoarse Professional Services, 691 Chelham Way, Santa Barbara, California 93108, U.S.A.
}

\begin{abstract}
The mixing of magmas of distinct temperature, bulk composition, mineralogy, and physical properties plays a central role in explaining the diversity of magma types on Earth and in explaining the growth of continental and oceanic crust. Magma mixing is also of practical importance. For example, the mixing of distinct magmas has been cited as an important process in creation of economically important horizons in layered intrusions as well as a triggering mechanism for initiation of volcanic eruptions. The motivation for better quantifying the dynamics and thermodynamics of magma mixing and its attendant plutonic and volcanic products is clear. The degree of magma mixing, which spans a continuum from mingling to complete hybridization, depends upon initial and boundary conditions, magma properties, driving forces, and time available for mixing. Magma mingling produces a heterogeneous mixture of discrete clumps of the end-member magmas, whereas complete hybridization involves the thermodynamic equilibration of two distinct magmas to form a third. Qualitatively, mixing occurs via reduction in the size of compositional heterogeneities (i.e., clumps) through stretching and folding by viscous flow, followed by homogenization, once shear has reduced the size of compositional anomalies to diffusive length scales. Quantification of this process relies on two statistical measures: the linear scale of segregation $(\Lambda)$ defined as the spatial integral of the compositional correlation function related to the size-distribution of the segregated clumps within the mixture, and the intensity of segregation $(I)$ a measure that quantifies how much the composition at each location differs from the average. The mixing dynamics of a layered system are analyzed in terms of the parameters governing mixing (Rayleigh, Lewis, and buoyancy numbers and viscosity ratio) to estimate how the timescale for magma hybridization, $\tau_{\mathrm{H}}$, compares to solidification, recharge, diffusive, and assimilation timescales. This analysis illustrates that hybridization times can be shorter than or comparable to thermal, solidification, and replenishment timescales; thus, formation of hybridized or nearly hybridized magmas is one anticipated outcome of mixing. The machinery of thermodynamics can be used to compute the hybrid magma state. An exploratory model for the thermochemistry of hybridization is developed based on binary eutectic phase relations and thermodynamics. Eight thermodynamic parameters define the phase diagram and associated energetics, and six parameters (initial temperatures, compositions, mass ratio of mixing magmas, and an enthalpy parameter) are necessary and sufficient to determine the state of hybrid magma uniquely. While relevant combinations of 14 thermodynamic and mixing parameters might suggest that the number of mixing outcomes (i.e., products) is too high to systematize, Monte Carlo simulations using the exploratory model document how millions of arbitrary initial states evolve into five possible final (mixed) states. Such an analysis implies that a magma mixing taxonomy that defines possible mixed product states can be developed and tied to petrologic indicators of mixing. Additional insights gained from this exploratory model that are supported by independent results from a multicomponent, multiphase thermodynamic model of magma mixing (Magma Chamber Simulator) include: (1) the proclivity of invariant point hybrid states, which may explain some instances of compositionally monotonous melts associated with mixed magma eruptions; (2) a surprising thermal effect such that the temperature of hybridized magma can be significantly less than the initial temperature of either of the mixing magmas. This type of magma mixing may result in crystal resorption, thus invalidating an assumption that resorption textures in crystals are typically the result of a magma heating event; (3) illustration of the differing effects of stoped block temperature and composition on hybrid magma temperature and phase state; and (4) illustration of a cessation of crystallization effect that may pertain to the MORB pyroxene "paradox." Differences between adiabatic or R-hybridization and diabatic or RFChybridization are also explored. The model can be used to elucidate the thermodynamic principles underlying magma mixing in the hybridization limit. These principles are of general applicability and carry over to more compositionally complicated systems.
\end{abstract}

Keywords: Magma mixing, hybridization, thermodynamics, recharge

\footnotetext{
*E-mail: spera@geol.ucsb.edu

Special collection papers can be found online at http://www.minsocam.org/MSA/

AmMin/special-collections.html.
} 


\section{INTRODUCTION}

The proposition that the mixing of magmas of distinct temperature, bulk composition, and phase state (i.e., phase composition and abundance) is an important petrogenetic process is almost as old as the discipline of igneous petrology (Bunsen 1851; see Wilcox 1999 for historical review). Abundant evidence in support of magma mixing (mafic magma addition to resident silicic magma or vice versa) is derived from studies of mafic enclaves in plutonic rocks (e.g., Pabst 1928; Didier and Barbarin 1991), syn-plutonic mafic or silicic dikes within intrusive bodies (e.g., Blake et al. 1965; Wiebe 1973; Reid et al. 1983; Furman and Spera 1985; Wiebe 1987, 1996; Baxter and Feely 2002; Gibson et al. 2003; Wiebe and Hawkins 2015) and from abrupt changes in cumulate rock modes and phase compositions in layered intrusions (e.g., Wager and Brown 1968; Irvine 1970; McCallum et al. 1980; DePaolo 1985; Eales 2002; Morse 2008; Vantongeren and Mathez 2013). Additionally, mixed-pumice eruptions (e.g., Anderson 1976; Smith 1979; Eichelberger 1980; Bacon 1986; Nakamura 1995; Coombs et al. 2000; Eichelberger et al. 2013) and crystal-scale heterogeneity in phenocrysts and cumulate minerals (e.g., Dungan 1987; Stelten et al. 2013; Humphreys et al. 2013) provide prima facie evidence for the mixing of magmas. Magma recharge and mixing are key elements of modern theories of petrogenesis, and the significant contribution magma mixing makes to petrogenesis in a range of petrotectonic environments including MORB (Walker et al. 1979), Island Arcs (Sakuyama 1984), and Ocean Island Basalts (OIB) (Kamber and Collerson 2000) cannot be overemphasized. The key point is that magmas evolve in open systems exchanging heat and material with their surroundings. Magma recharge is an important agent of this dynamical behavior.

The dynamics of viscous fluid (sensu lato) mixing is a complex subject with an extensive literature (e.g., see reviews in Ottino 1989; Haller 2001; Voth et al. 2002). Mixing is widespread in nature and in myriad technological applications. In the geosciences, mixing is relevant to the oceans (Poje and Haller 1999), atmosphere (Koh and Legras 2002), mantle (Farnetani and Samuel 2003; Tackley 2007; Le Bars and Davaille 2004a), and at smaller scales in continental hydrological, hydrothermal, and magmatic systems. In this work, attention is focused upon the dynamics and thermodynamics of magma mixing. In particular, the dynamics of magma mingling and mixing is examined for a canonical layered magma body to provide estimates of the magma hybridization time. This is the time required for two initially distinct magmas to intimately hybridize and achieve thermodynamic equilibrium.

When two magmas are stirred together, a wide range of outcomes is possible. A particular outcome depends upon the imposed initial and boundary conditions, the initial spatial configuration of the magmas, magma thermodynamic and transport properties, the relative forces that drive mixing, and the time available for mixing before arrest by freezing (plutonic) or quenching (eruption). In broad terms, the phenomenon of mixing is simply viewed as the progressive (temporal) eradication of compositional heterogeneities (i.e., clumps) by stretching and folding due to the action of viscous shearing forces. Pressure, buoyancy, and inertial forces potentially contribute to these motions. Once shear mixing has reduced the size of chemical anomalies to diffusive length scales, homogenization is achieved by chemical diffusion (Ottino 1989).

Historically, when magma mixing has been invoked as a petrogenetic hypothesis the terms "mingling" and "hybridization" have been used differently by different geologists. To be precise, the following conventions are used in this work. Magma mixing occurs along the spectrum from mingling to hybridization. Mingling of magmas produces a heterogeneous mixture containing discrete portions (clumps) of the end-member magmas (hereafter called $\mathbf{M}$ for resident magma and $\mathbf{R}$ for recharge magma). The final product comprises spatially discrete portions of each magma type distributed heterogeneously within the magma body. Hybridization involves the mixing and thermodynamic equilibration of two or more distinct magmas to form a chemically and physically homogeneous magma (hereafter called $\mathbf{H}$ for hybrid magma). Magma hybridization can be studied as an adiabatic (isenthalpic) or diathermal (diabatic) process. It is noted that whereas the dynamics of magma mixing is indeed a very complicated fluid dynamical problem, in the hybridization limit, the machinery of equilibrium thermodynamics allows determination of the state of hybridized magma provided appropriate and sufficient thermodynamic data are available without recourse to dynamics per se. It is important to note that "perfect" hybridization (as defined here) generates a homogeneous magma that preserves no record of the mixing process itself. It represents a thermodynamic equilibrium limit. In practice, one may anticipate that there exists a "scale of scrutiny" below which heterogeneity reigns. In a later section, a statistical quantity, the linear scale of segregation $(\Lambda)$, is introduced to quantify the extent of heterogeneity. This statistical measure of dimension length allows one to gauge the spatial scale at which the magma body is indeed mixed. Finally, it is noted that although, as defined in this study, a hybrid (homogeneous) magma results from the complete mixing of two (or more) end-member magmas, not every homogeneous magma is the result of hybridization. For example, partial melting of a source at or near an invariant point can generate a homogeneous magma that has nothing to do with magma mixing.

The purpose of this study is twofold. In the first part, a brief treatment of magma mixing dynamics is presented to illustrate how the extent of mixing can be quantified using simple statistical measures. Estimates for magma hybridization times as a function of the critical parameters for an initially compositionally layered system are presented. Analysis shows that hybridization times can be shorter than or comparable to thermal, solidification and replenishment timescales (Oldenburg et al. 1989; Petrelli et al. 2011), a feature that facilitates the formation of hybridized magma following mixing of two distinct magmas. The second goal is to develop and apply a simple exploratory model of the thermochemistry of magma hybridization for both adiabatic and diabatic mixing. The model is based on a binary system (e.g., $\mathrm{CaMgSi}_{2} \mathrm{O}_{6}-\mathrm{CaAl}_{2} \mathrm{Si}_{2} \mathrm{O}_{8}$ ) with simple thermodynamics (ideal mixing, eutectic phase equilibria, no crystalline solution). The function of this exploratory or "toy" model is to elucidate the principles of magma hybridization without any obfuscating details (e.g., Larson et al. 2014). The "toy" model of Dyson (2000) pertaining to the origin of life is a classic example illustrating the power and role toy models play in the elucidation of the fundamental aspects of a complex natural system, 
whether biological or physiochemical. For magma mixing, the effects of arbitrary variations in bulk composition, temperature, and mixing ratio ( $\mathbf{M}$ to $\mathbf{R}$ ) on hybridization outcomes are explored in temperature-enthalpy-composition coordinates. Behaviors observed in the exploratory model also appear in more complete multicomponent-multiphase calculations using the Magma Chamber Simulator (MCS, Bohrson et al. 2014) and highlight the resulting challenges to identify associated characteristics in natural mixed systems. A key conclusion from numerous simulations using the exploratory and MCS models is that magma (multiphase) mixing is very different than the mixing of two melts to form a third homogeneous melt. When two melts blend to form a third melt, the final temperature of the hybridized melt is the mass-weighted average of the temperatures of the mixing liquids (unless the heat of mixing is very different than zero, which is rarely the case in silicate liquid mixing), and the final melt composition is the weighted average of the compositions of $\mathbf{M}$ and $\mathbf{R}$ melts. But the mixing of aphyric melts is uncommon because superheated magmas are rare in Nature (Carmichael et al. 1974). These melt-melt mixing relations are not followed when two magmas mix, and thus intuition about mixing developed using melt-melt mixing relations may lead to erroneous conclusions about the mixing process and products. As we demonstrate, the temperature of the hybrid magma can be below that of $\mathbf{M}$ and $\mathbf{R}$, and the melt composition can be markedly different than the bulk composition of the hybrid magma. Exploration of the possible outcomes of magma hybridization using the toy model therefore provides insight into the thermochemistry of magma mixing in Nature and permits identification of characteristics of mixed systems that may have gone previously unrecognized. An excellent guide to the application of magma mixing thermodynamics to MORB magmas is given in Walker et al. (1979).

\section{QUANTIFICATION OF MAGMA MIXING: Mingling VS. HYBRIDIZATION}

\section{Magma mixing definition and terminology}

Magma mixing is the process of bringing two initially distinct magmas together and allowing an approach to equilibrium to be made. In magma mingling two initially distinct magmas, $\mathbf{M}$ and $\mathbf{R}$, remain compositionally distinct (e.g., as discrete co-mingled volumes of one within the other) except for very thin (millimeter to centimeter) interfacial diffusive boundaries. In magma hybridization, $\mathbf{M}$ and $\mathbf{R}$ thoroughly mix and thermodynamic equilibrium is achieved. The resultant hybrid magma $(\mathbf{H})$ is a mixture of homogeneous melt, unzoned crystals, and bubbles of supercritical fluid (when fluid saturated). In $\mathbf{H}$ magma, all coexisting phases are at a unique and identical temperature and pressure, and the chemical potentials of all components in all phases are equal. Hybridization is thus a unique end-member state of the phenomenon of magma mixing. When hybridization occurs at constant enthalpy (isenthalpic), no heat is removed from the system and hence the enthalpy of the hybrid magma (H) is identical to the sum of the (appropriately mass-weighted) enthalpies of $\mathbf{M}$ and $\mathbf{R}$ magmas (the mixing "components"). This process is defined as Recharge-hybridization or R-hybridization. Alternatively, when mixing is accomplished under diathermal conditions (i.e., diabatic mixing), the ratio of the enthalpy of
$\mathbf{H}$ magma $\left(\mathrm{h}^{\mathrm{H}}\right)$ to the sum of the mass-weighted enthalpies of $\mathbf{M}$ and $\mathbf{R}\left(\mathrm{h}^{\mathrm{M}}\right.$ and $\mathrm{h}^{\mathrm{R}}$, respectively) is $\Phi(0<\Phi<1)$. Diathermal mixing is termed RFC-hybridization since the hybridized magma reflects concurrent recharge, performed isenthalpically, and crystallization, a diabatic process driven by heat removal. Crystallization can be either fractional or equilibrium. In natural systems, crystallization is usually closer to fractional than equilibrium, although "perfect" fractional crystallization is rarely attained. Incremental batch crystallization is probably a better model, in general (Langmuir 1989; Bohrson et al. 2014). Although not pursued in this study, partial melting can also be studied using the toy model by allowing $\Phi>1$. In this case, the ratio of the enthalpy of the hybrid magma to the enthalpy of the mass-weighted average of distinct crystalline sources ( $\mathbf{M}$ and R) equals $\Phi$ with $\Phi>1$. Physically, this corresponds to partial melting driven by addition of heat to a crystalline source.

\section{Quantitative measures of magma mixing}

It is important to establish quantitative measures of the "goodness of mixing." Indeed, many methods have been developed to analyze the time-dependence of mixing dynamics. These include, for example, mapping of Poincare sections, the determination of finite-size and finite-time Lyapunov exponents from concentration variations in space and time, and calculation of hyperbolic persistence times. Mixing time estimates extracted from these measures involve knowledge of velocity, temperature and compositional fields for particular flow configurations with well-defined boundary and initial conditions and rely on sophisticated mathematical manipulations of these data (e.g., Liu et al. 1994; Farnetani and Samuel 2003; van Keken et al. 2003; Tackley 2007). These methods are difficult if not impossible to apply to "snapshots" of magmatic systems observed in the field when studying volcanic and plutonic rocks, however. To overcome this problem, two statistical parameters, developed by Danckwerts $(1953 a, 1953 b)$ for chemical reactor analysis and applied by Oldenburg et al. (1989) and Todesco and Spera (1992) to magma mixing, are considered here. These statistical measures are the linear scale of segregation $\Lambda$ and the intensity of segregation I. The advantage of these metrics is that they can be applied independent of knowledge of the temporal evolution of the mixing process because they solely utilize information on the observed spatial pattern of heterogeneity. That is, they can be applied to a "snapshot" of a compositional field.

Magma mingling is characterized by a reduction in size of compositional anomalies (deviations from the mean composition), and the linear scale of segregation $(\Lambda)$ is useful in quantifying the mixing state of the system in terms of its "clumpiness." The linear scale of segregation is based upon deviations from the mean defined by $C_{1}-\bar{C}$ and $C_{2}-\bar{C}$ where $C$ is shorthand for an array of compositional variables such as the mass fraction of oxide components or the concentration of a trace element and the subscripts refer to distinct locations in Euclidean space within the mixing domain separated by distance $r$. In well-mixed (homogenous) magma, such deviations are identically zero everywhere. The average of the product of these deviations over many distinct pairs all distance $r$ apart is denoted

$$
\overline{\left(C_{1}-\bar{C}\right)} \overline{\left(C_{2}-\bar{C}\right)} \text {. }
$$


If this summation is repeated over all possible pair separation distances (i.e., different values of $r$, the separation distance) and the resulting quantity is divided by the mean-square compositional deviation (the variance)

$$
\overline{(C-\bar{C})^{2}}
$$

then a normalized correlation function

$$
R(r)=\frac{\overline{\left(C_{1}-\bar{C}\right)} \overline{\left(C_{2}-\bar{C}\right)}}{(C-\bar{C})^{2}}
$$

is formed. It is noted that when $r=0, C_{1}=C_{2}$, and $R(0)=1$; that is, at separation distance zero, the mixture is completely segregated. In general, values of $R(r)$ near 1 mean that a concentration greater or less than the mean at some point in the magma is likely to be correlated with a similar positive or negative compositional anomaly a distance $\mathrm{r}$ away. If $R(r)=0$, a random relationship exists between concentrations at the two locations separated by distance $r$. A value of $R(r)$ near -1 means that there is a perfect anti-correlation between the magma compositions at the two locations, for instance, if pure "silicic" melt is at one location and pure "basalt" is at the other. The linear scale of segregation $\Lambda$ is defined as the integral of the normalized correlation function

$$
\Lambda=\int_{0}^{r_{\max }} R(r) d r .
$$

Because $\Lambda$ is evaluated over a large range of $r$, it is a measure of the "lumpiness" of the compositional anomalies at spatial scales greater than typical diffusive scales that are of order millimeters to centimeters in magmas.

A second metric, the intensity of segregation I, is a scalar measure of magma homogeneity relating the compositional anomaly at a given location relative to the mean composition $(\bar{C})$ over the volume of the body. The intensity of segregation $(I)$ is defined

$$
I=\frac{\overline{(C-\bar{C})^{2}}}{\overline{\bar{C}(1-\bar{C})}}
$$

where the numerator is the variance of the compositional field. The intensity of segregation is essentially a rescaled variance. It measures how much the composition at each point differs from the average composition of the mixture. $I$ has the value of 1 when segregation is complete (e.g., the concentration at every point is either "silicic" or "basaltic"), and $I=0$ when the composition is uniform and the mixing end-members have been hybridized to form a homogeneous magma. I reflects neither the relative amounts of the two initially distinct magmas nor the size of the clumps. Instead, I measures the extent to which the initially distinct magmas vary in composition from the spatial average throughout the mixing domain. A perfectly clumpy two "component" mixture with no intermediate composition has an intensity $(I)$ of unity no matter what the size of the clumps may be.

Qualitatively, the linear scale of segregation $(\Lambda)$ can be pictured as the size of the segregated clumps within the mixture, while the intensity of segregation $(I)$ describes the difference in composition between a clump and surrounding magma. Small-scale mixing in magmas proceeds by decreasing both the scale and intensity of segregation. The intensity of mixing is a monotonically decreasing function of time due to diffusion, in accordance with the Second Law of Thermodynamics. The scale of segregation, although eventually decreasing to zero when hybridization is complete, does not necessarily do so monotonically (Oldenburg et al. 1989 and see below). It is recognized that any magmatic mixture, if examined closely enough, will show regions where the composition varies from point to point. The maximum size of a segregated region varies depending upon the level of scrutiny commensurate with the objectives of the petrologic study.

Based on the indices of the "goodness of mixing" defined above, some limiting cases can be described. At the initiation of mixing, $I$ is equal to unity and $\Lambda$ is equal to some maximal linear scale depending on the pre-mixing configuration. For example, for the canonical "before mixing" configuration of a layered magma body such as silicic "cold" magma of thickness $\lambda_{\mathrm{s}}$ atop an equal thickness of mafic "hot" magma, the linear scale of segregation at $t=0$ is simply $\lambda_{\mathrm{s}}$. In any mixing process with nonzero diffusion, $I \rightarrow 0$ as $t \rightarrow \infty$ because once normal and shear strain reduces compositional anomalies to diffusive lengths, the anomalies are erased by molecular diffusion. Similarly, as $t \rightarrow \infty$, $\Lambda \rightarrow 0$ since the linear scale of segregation evolves to zero after a sufficiently long duration of stirring when clumps are vanishingly small. Of course the crux of the issue in magma mixing is to quantify precisely the duration of a "sufficiently long" time interval. To make estimates of the mixing time in general is not easy; a plethora of details regarding the flow dynamics and configuration and properties of the mixing magmas must be defined quantitatively. Fortunately, for the canonical arrangement of a layered magma system, enough is known presently to make rough estimates of mixing times. In the following section this problem is considered in more detail.

\section{Magma mixing dynamics}

Although incomplete magma mixing, evidenced by petrographic and field-scale disequilibrium features, is ubiquitous, examples of magmas hypothesized to originate via hybridization, of two initially distinct end-member magmas are not uncommon (e.g., Dunham and Wadsworth 1978; Hibbard 1981, 1991; Browning 1984; Dungan 1987; Gibson et al. 2003; Appleby et al. 2008). Accordingly, before discussing the thermodynamics of hybridization, a discussion of the dynamics of mixing with emphasis on the factors that control the time required for two magmas to mix sufficiently thoroughly to approximate the hybridized state $(I \approx 0$ and $\Lambda \approx 0)$ is presented. The main conclusion is that hybridization timescales are of the same order or less than timescales associated with magma cooling, crystallization and magma chamber growth itself. It is therefore reasonable to expect to encounter examples where magma hybridization has gone to completion or nearly to completion in natural systems. Indeed, as noted above, many such examples can be found by examination of the petrological literature. It is emphasized that the "level of scrutiny" is an important aspect in recognizing the attainment of hybridization. In the strict sense, a hybridized magma has $I=\Lambda=0$, exactly. In practice, the level of scrutiny, 
defined as a length scale, comes into play in the determination of whether magma mixing has created a hybrid magma. If zonation in phenocrysts can be "tolerated," then $\Lambda \approx 1 \mathrm{~mm}$. If the level of scrutiny is zoning at the small crystallite scale, $\Lambda \approx 10 \mu \mathrm{m}$. On the other hand if the scale of scrutiny is no smaller than typical glomeroporphyritic clots, then hybridization has been achieved to the limit of $\Lambda \approx 10^{-2} \mathrm{~m}$.

The magma hybridization timescale $\left(\tau_{\mathrm{H}}\right)$ is the time interval following the onset of magma mixing required for the distinct magmas to achieve thermodynamic equilibrium via the mixing process. Quantitatively, this implies a hybrid $(\mathbf{H})$ magma with mixing statistics of $I \rightarrow 0$ and $\Lambda \rightarrow 0$, where the practical limit is based on an appropriate "scale of scrutiny" based on the type of petrologic study and geochemical tools used to characterize the state of the system (e.g., field, petrographic, microprobe, laser ablation of single phenocrysts, etc.). Once defined, $\tau_{\mathrm{H}}$ can be compared with solidification, recharge, diffusive and assimilation timescales to recognize the chronological dynamics of petrogenesis [e.g., see discussion in Bohrson et al. (2014) for these scales]. When the hybridization timescale is less than other transport timescales, magma mixing can approach "completion" and hybrid magma is formed. Unfortunately, there is no comprehensive picture of possible mixing outcomes for arbitrary mixing scenarios. In this study, attention is focused on the dynamics of mixing for the simple case of an initially layered magma body. This is an archetypical configuration; many previous numerical, laboratory, and field studies (e.g., Sparks et al. 1977; Huppert et al. 1982; Olson et al. 1984; Clark et al. 1987; Oldenburg et al. 1989; Todesco and Spera 1992; Wiebe 1996; Jellinek and Kerr 1999; Davaille 1999a, 1999b; Le Bars and Davaille 2002, 2004a, 2004b; Petrelli et al. 2006, 2011) have focused on this configuration in an effort to approximately estimate the dependence of hybridization time on magma properties and volumes.

The geometry, magma properties, and boundary conditions of the mixing configuration are depicted in Figure 1. In Table 1, all parameters are defined. For simplicity, it is assumed that the starting $\mathbf{M}$ and $\mathbf{R}$ compositions are one-phase liquids to avoid phase equilibria considerations. The melt density is a function of temperature $(T)$ and composition, where $C$ is the mass fraction of light component, and $\mathbf{M}$ and $\mathbf{R}$ refer to the distinct magmas that are mixed and subsequently hybridized. Following Clark et al. (1987), the equation of state is

$$
\rho(T, C)=\rho_{\mathrm{T}_{\mathrm{O}}^{\mathrm{R}}, C_{\mathrm{O}}^{\mathrm{R}}}\left[1-\alpha_{T}\left(T-T_{\mathrm{O}}^{\mathrm{R}}\right)-\alpha_{C}\left(C-C_{\mathrm{O}}^{\mathrm{R}}\right)\right]
$$

where the reference density, $\rho_{\mathrm{T}_{\mathrm{O}}^{\mathrm{R}}, \mathrm{C}_{\mathrm{O}}^{\mathrm{R}}}$, is the melt density at the initial temperature and composition of the bottom $(\mathbf{R})$ layer where $T$ $=T_{\mathrm{o}}^{\mathrm{R}}=T_{\mathrm{b}}$ and $C=C_{\mathrm{o}}^{\mathrm{R}}, \alpha_{\mathrm{T}}$ and $\alpha_{\mathrm{C}}$ are the melt thermal and chemical expansivities, respectively, and $\rho$ is melt density. It is convenient to use dimensionless variables for temperature and composition. These are defined $\hat{T}=\left(T-T_{\mathrm{o}}^{\mathrm{M}}\right) /\left(T_{\mathrm{o}}^{\mathrm{R}}-T_{\mathrm{o}}^{\mathrm{M}}\right)$ and $\hat{C}=\left(C-C_{\mathrm{o}}^{\mathrm{R}}\right) /\left(C_{\mathrm{o}}^{\mathrm{M}}\right.$ $\left.-C_{\mathrm{o}}^{\mathrm{R}}\right)$. In the initial state, the difference in density between $\mathbf{R}$ (bottom layer) and $\mathbf{M}$ (top layer) is $\Delta \rho=\rho_{\mathrm{T}^{\mathrm{R}}, \mathrm{C}^{\mathrm{R}}}\left(\alpha_{C} \Delta C-\alpha_{T} \Delta T\right)$ where $\Delta T=T_{\text {bottom }}-T_{\text {top }}, \Delta C=C_{\mathrm{o}}^{\mathrm{M}}-C_{\mathrm{o}}^{\mathrm{R}}$ and the reference density is the density of melt at $T=T_{\mathrm{o}}^{\mathrm{R}}-T_{\mathrm{b}}$ and $C=C_{\mathrm{o}}^{\mathrm{R}}$. For example, if dacitic melt sits atop andesitic melt and composition is parameterized on mass fraction silica, typical parameters are $T_{\mathrm{o}}^{\mathrm{R}}=1373 \mathrm{~K}$, $T_{\mathrm{o}}^{\mathrm{M}}=T_{t}=1173 \mathrm{~K}, \alpha_{\mathrm{C}}=0.8, \alpha_{\mathrm{T}}=4 \times 10^{-5} \mathrm{~K}^{-1}, C^{\mathrm{M}}=0.7, C^{\mathrm{R}}=0.6$

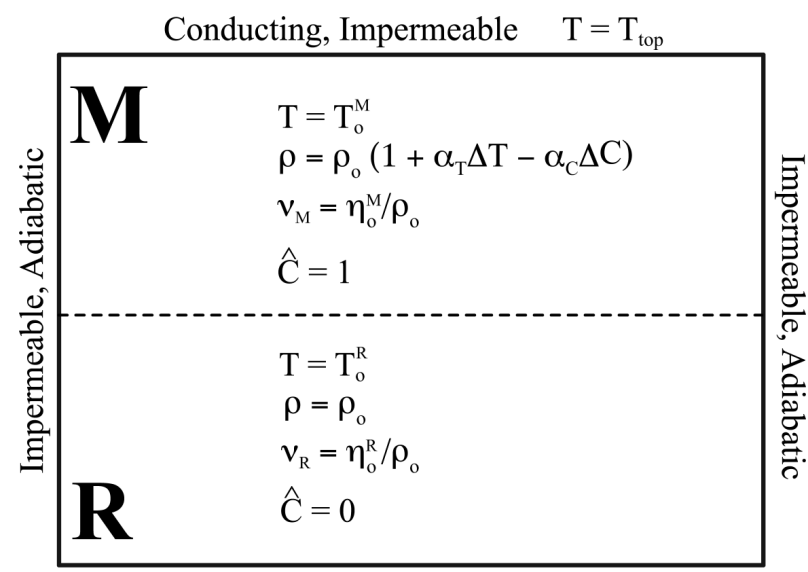

Conducting, Impermeable $\quad \mathrm{T}=\mathrm{T}_{\text {bottom }}$

FIGURE 1. Schematic representation of initial conditions and magma properties for canonical magma mixing scenario. Magmas $\mathbf{M}$ and $\mathbf{R}$ are initially layered inside an impermeable box with adiabatic sidewalls and perfectly conducting horizontal walls. $\mathbf{M}$ and $\mathbf{R}$ possess unique compositions and properties. If $\mathbf{R}$ is denser than $\mathbf{M}$ (regardless of $T$ or $C)$, little mixing will occur except for negligible interfacial chemical diffusion. If $\mathbf{R}$ is in its initial state less dense than $\mathbf{M}$, mixing will rapidly initiate. When temperature and compositional differences are opposing and both contribute significantly to density, complicated unsteady mixing regimes occur. See text for discussion and Table 1 for definitions.

TABLE 1. Nomenclature and variable definitions for magma mixing dynamics

\begin{tabular}{|c|c|c|}
\hline Quantity & Units & Definition \\
\hline$\rho$ & $\mathrm{kg} / \mathrm{m}^{3}$ & Density \\
\hline$\alpha_{T}$ & $\mathrm{~K}^{-1}$ & Isobaric expansivity \\
\hline$\alpha_{c}$ & & Chemical expansivity \\
\hline$T$ & $\mathrm{~K}$ & Temperature \\
\hline C & & Mass fraction light component \\
\hline$\hat{T}$ & & Dimensionless temperature \\
\hline$\hat{C}$ & & Scaled composition \\
\hline g & $\mathrm{m} / \mathrm{s}^{2}$ & Gravity acceleration \\
\hline$\Delta T=T_{\mathrm{b}}-T_{\mathrm{t}}$ & $\mathrm{K}$ & Temperature difference (Fig. 1) \\
\hline$\Delta C=C_{0}^{\mathrm{M}}-C_{0}^{\mathrm{R}}$ & & Compositional difference (Fig. 1) \\
\hline d & $\mathrm{m}$ & Total layer depth \\
\hline$\kappa$ & $\mathrm{m}^{2} / \mathrm{s}$ & Thermal diffusivity \\
\hline$v_{R}$ & $\mathrm{~m}^{2} / \mathrm{s}$ & Kinematic viscosity of bottom layer \\
\hline D & $\mathrm{m}^{2} / \mathrm{s}$ & Chemical diffusivity \\
\hline$B=\frac{\alpha_{\mathrm{C}} \Delta C}{\alpha_{\mathrm{T}} \Delta T}$ & & Buoyancy number \\
\hline$R a=\underline{\alpha_{\mathrm{T}} \mathrm{g} \Delta T \mathrm{~d}^{3}}$ & & \\
\hline$v_{\mathrm{R}} \mathrm{K}$ & & Rayleigh number \\
\hline$L e=\mathrm{K} / D$ & & Lewis number \\
\hline$v_{r}=\frac{v_{\mathrm{M}}}{v_{\mathrm{R}}}$ & & Ratio of kinematic viscosities \\
\hline$\delta$ & $\mathrm{m}$ & Thickness of diffusive interface \\
\hline$h_{\mathrm{c}}$ & $\mathrm{m}$ & Thickness of unstable layer \\
\hline$\eta$ & Pa s & Dynamic viscosity \\
\hline V & $\mathrm{m} / \mathrm{s}$ & Velocity of Rayleigh-Taylor layer \\
\hline I & & Intensity of segregation \\
\hline$\Lambda$ & $\mathrm{m}$ & Linear scale of segregation \\
\hline$\underline{\tau_{i}}$ & $\mathrm{~s}$ & Timescale of $\mathrm{i}^{\text {th }}$ process \\
\hline
\end{tabular}

Notes: $\mathrm{R}=$ Recharge magma; $\mathrm{o}=$ Initial or reference value; $\mathrm{b}=$ Bottom boundary; $\mathrm{M}=$ Resident magma; $\mathrm{H}=$ Hybridized magma. 
and hence $\Delta \rho \approx 200 \mathrm{~kg} / \mathrm{m}^{3}$ for a reference density of $2700 \mathrm{~kg} / \mathrm{m}^{3}$ (i.e., $\mathbf{R}$ magma is $200 \mathrm{~kg} / \mathrm{m}^{3}$ denser than $\mathbf{M}$ magma in the initial state). Values of $\alpha_{C}$ for various oxide components may be found in Clark et al. (1987). Values of $\alpha_{C} \Delta C$ depend on the particular oxide component and the compositional differences between the layers. For the extreme case of a basalt-rhyolite layered arrangement, the magnitude of the product $\alpha_{C} \Delta C$ varies from $\sim 0.01$ to 0.3 for the major oxide components. The two largest values are for silica (0.13) and $\mathrm{H}_{2} \mathrm{O}(0.3)$; thus, the importance of having quantitative constraints on the $\mathrm{H}_{2} \mathrm{O}$ content of the end-member mixing magmas is obvious. A typical value for $\alpha_{\mathrm{T}} \Delta T$ is $\sim 0.01$. This shows that, in general, buoyancy effects due to differences in composition outweigh those due to temperature. The dynamical significance of this is discussed below.

The dimensionless parameters that govern the stability and evolution of the layered arrangement of Figure 1 include the thermal Rayleigh number,

$$
R a=\frac{\alpha_{\mathrm{T}} g \Delta T d^{3}}{\nu_{\mathrm{R}} \kappa},
$$

the buoyancy number (the ratio of chemical to thermal buoyancy),

$$
B=\frac{\alpha_{C} \Delta C}{\alpha_{T} \Delta T},
$$

the Lewis number, $L e=\kappa / D$ (where $\kappa$ is the thermal diffusivity and $D$ is the diffusivity of chemical species), the kinematic viscosity ratio $v_{\mathrm{r}}=v_{\mathrm{M}} / v_{\mathrm{R}}$, and the thicknesses of the two layers. (See Table 1 for definitions of equation parameters not given here.) The kinematic viscosity ratio depends on $T$ and $C$, although typically the $C$-dependence is more important (Spera 2000). In what follows, the layers are of identical thickness for simplicity. In magma systems, $R a$ varies widely, from $10^{8}-10^{16}$ or larger due mainly to the range in magma body size $\left(d \sim V^{1 / 3} ; V\right.$ is magma body volume) and to a lesser extent on magma kinematic viscosity. $L e$ is typically large, of order $10^{5}$ for most chemical species. Range for the buoyancy number $B$ is discussed below.

The effects of $R a, L e$, and $B$ have been studied by laboratory and numerical methods for the layered arrangement of Figure 1 for a limited range of the governing parameters; these results can be applied to magma mixing scenarios, approximately. A useful way to discuss magma mixing scenarios is to hold $R a$ and $L e$ fixed and study the effects of the buoyancy number $B$ on flow dynamics, entrainment rates, and hybridization times. The discussion that follows assumes $R a \sim 10^{8}$ and $L e \sim 10^{5}$ as a starting point because these values have been studied experimentally and because simulations at much higher Rayleigh numbers are not practical due to computational resource limitations. Although this may appear as a severe limitation, scaling studies show that hybridization times scale as $\tau_{\mathrm{H}} \sim R a^{-1} B^{2} L e^{1 / 2} \nu_{\mathrm{r}}^{1 / 2}$ (Oldenburg et al. 1989; Petrelli et al. 2011). Hence, the effects of more realistic Ra values can be approximated using this scaling relationship. Note that the hybridization timescale depends most strongly on buoyancy number $B$.

In general $B$ can be positive, zero, or negative. For $B>1$, compositional buoyancy is strong and a stable stratification develops (e.g., "rhyolite over basalt"). Although each layer may experience internal convective overturn due to the temperature gradient, the interface between the two compositions remains flat and entrainment rates and mass exchange between layers is small. For $B>>1$, mass exchange is governed solely by diffusion with very limited entrainment (mass exchange) between the layers. The interfacial diffusive layer thickness scales as $\delta=\sqrt{D} t$ where $t$ is the duration of contact. Based on a tracer diffusivity of oxygen in a silicate melt of $10^{-12} \mathrm{~m}^{2} / \mathrm{s}$ at $1500 \mathrm{~K}$ (Lesher and Spera 2015), diffusive boundary layer thicknesses are $0.8 \mathrm{~mm}, 1.6 \mathrm{~mm}, 5.6 \mathrm{~mm}, 1.8 \mathrm{~cm}, 5.6 \mathrm{~cm}$, and $0.18 \mathrm{~m}$ for durations of a week, month, year, decade, century, and millennium, respectively. These chemical boundary layers are much thinner than characteristic lengths of magma bodies, consistent with minimal mass exchange. Because conductive transfer of heat is faster than species diffusion by $\sim 10^{5}$ or more, heating of the overlying silicic magma advances more quickly. For example, heat travels $0.5,1,3.5,11$, and $110 \mathrm{~m}$ for durations of a week, month, year, decade, century, and millennium, respectively. Thus, for $B>>1$, the lower part of the top layer will acquire positive thermal buoyancy if heated from below. When the thickness of the basal thermal layer $h_{c}$ exceeds a critical value, the layer will be unstable (unless stabilized by internal layer compositional buoyancy), detach and flow upward as a buoyant plume. The thickness of the basal layer is approximately $\mathrm{h}_{\mathrm{c}}=\left(\kappa \eta^{\mathrm{M}} R a_{\text {crit }} /\right.$ $\left.\rho_{o} \alpha^{\mathrm{M}} \Delta T g\right)^{1 / 3}$. For typical values appropriate for an andesitic bulk composition and $R a_{\text {crit }}=10^{3}$, the critical thickness is several meters (Spera 2000). This layer can develop within weeks after $\mathbf{R}$ and $\mathbf{M}$ are juxtaposed. The stirring and decompression associated with ascent of the thermally buoyant layer (plume) could in turn trigger an instability driven by volatile exsolution via Rayleigh-Taylor instability. For example, if basal layer $\mathbf{M}$ magma happens to be close to volatile saturation, then ascent and decompression could drive the magma locally to volatile saturation and potentially trigger dynamical behavior leading to an eruption. This is the eruption "trigger" mechanism of Sparks et al. (1977) and is contingent on the details of the $\mathrm{H}_{2} \mathrm{O}$ content of $\mathbf{M}$, local temperature and the vigor of plume ascent. The ascent velocity, when a plume detaches can be roughly estimated for this Rayleigh-Taylor instability by balancing viscosity against thermal buoyancy according to

$$
v \approx \frac{g \rho_{0} \alpha \Delta \mathrm{Th}_{c}^{2}}{\eta} .
$$

Typical values appropriate for dacitic magma gives $\sim 0.01 \mathrm{~m} / \mathrm{s}$, which is quite rapid.

For $0.5<B<1$, dynamic topography develops along the interface with an amplitude that grows as $R a^{1 / 3}$, approximately (Gurnis and Davies 1986). This leads to moderate entrainment and the decrease in both the linear scale of segregation and intensity of segregation with time. For $B$ values, $0.3<B<0.5$, doming flow modes occur with extreme tilting of the interface (e.g., see Todesco and Spera 1992; Le Bars and Davaille 2004a, 2004b for examples from computation and laboratory experiments, respectively). In these flows, the linear scale of segregation decreases temporally (although not monotonically) as the interface between $\mathbf{M}$ and $\mathbf{R}$ sloshes to and fro. Domes of $\mathbf{R}$ within $\mathbf{M}$ oscillate with a period that depends on $R a$. The rate of change of segregation intensity $I$ is inversely proportional to $B$ and increases for increasing $R a$. At the lower end of the $\mathrm{B}$ range, dome heights approach 
layer thicknesses and rapid overturn, entrainment, and mixing can occur by "breaking wave" dynamics (e.g., Todesco and Spera 1993). In this case, small clumps ( $\sim 0.1 \mathrm{~m})$ of unmixed $\mathbf{M}$ and $\mathbf{R}$ magmas remain compositionally intact and crystals, some from $\mathbf{M}$ and some from $\mathbf{R}$, would be mixed, partially re-equilibrated and might exhibit complex disequilibrium features, especially when the viscosity ratio of the mixing magmas is large and for crystals with small intracrystalline diffusion rates like albiteanorthite zoning in plagioclase. Relatively unzoned crystals in local equilibrium with hybrid melt might also be present in regions where $\Lambda$ has produced small clumps of diffusive length scale $(\mathrm{mm})$ that can be eradicated in periods of order years to decade. This sort of complex textural and compositional evidence is ubiquitous in the geologic record (e.g., Clynne 1999; Landi et al. 2004; Salisbury et al. 2008; Tepley et al. 2000; Troll and Schmincke 2002). The timescale for this mixing is $0.3-0.5$ of the thermal timescale $\tau_{\mathrm{T}}=\mathrm{d}^{2} / \kappa$. For example, with $\mathrm{d} \sim 1 \mathrm{~km}$, the thermal timescale is $\tau_{\mathrm{T}} \approx 33 \mathrm{ka}$ and the hybridization timescale $\tau_{\mathrm{H}}$ is about $13 \mathrm{ka}$.

Finally, for $0<B<0.2$, rapid overturning occurs and mixing proceeds very rapidly in a small fraction $(\sim 0.05)$ of the thermal diffusion time. For scale, a $1 \mathrm{~km}$ thick $\mathbf{M}+\mathbf{R}$ layered system has a thermal timescale of $\sim 33 \mathrm{ka}$. Hence for small positive B, mixing is efficient within decades to centuries to a millennium depending most significantly on the volume of the system and magma physical properties.

For $B=0$, mixing of $\mathbf{M}$ and $\mathbf{R}$ liquids is driven solely by thermal convection. This is the special case of "passive" scalar or tracer mixing, for which there is no compositional buoyancy. That is, the chemical anomaly generates no intrinsic density difference and hence there is no buoyancy force due to composition. The mixing of two magmas of essentially identical major element bulk composition but different trace element concentrations would be an example of passive mixing (e.g., $\mathbf{R}$ magma is doped with a passive tracer, such as a trace element, with negligible effect on melt density). The hybridization time $\left(\tau_{\mathrm{H}}\right)$ for the mixing of a passive tracer can be estimated from models and numerical experiments (e.g., Kellogg and Turcotte 1990; Coltice and Schmalzl 2006) using scaling relations for high-Rayleigh number convection for velocity and boundary layer thicknesses from Spera (1992). Mixing occurs by Lagrangian stretching of clumps to sizes that are then erased by diffusion. Melt clumps may be of different viscosity. The hybridization time $\left(\tau_{\mathrm{H}}\right)$ depends weakly on the tracer diffusivity and is most sensitive to $R a$ and the thickness of the combined layers, d. For $\mathbf{M}$ and $\mathbf{R}$ of equal volumes and densities, the time for homogenization is

$$
\tau_{\mathrm{H}} \approx \frac{\mathrm{d}^{2} v_{\mathrm{r}}^{2 / 3}}{2 \kappa \mathrm{a}} R a^{-b} \ln \left(\frac{\mathrm{a} \kappa \nu_{\mathrm{r}}^{2 / 3} R a^{b}}{D}\right)
$$

where $\mathrm{a}=0.023$ and $\mathrm{b}=0.685$ are constants relating the Lagrangian bulk strain rate to the Rayleigh number. For typical parameters related to mixing of mafic and intermediate composition melts with a viscosity contrast of $100\left(\mathrm{~d}=1 \mathrm{~km}, \mathrm{v}_{\mathrm{r}}=100, \mathrm{\kappa}\right.$ $=5 \times 10^{-7} \mathrm{~m}^{2} / \mathrm{s}, \alpha=2 \times 10^{-5}, D=10^{-12} \mathrm{~m}^{2} / \mathrm{s}$ ), the mixing time is roughly 8 months, a tiny fraction of the thermal lifetime of the system. Note that the hybridization time scales as the $2 / 3$ power of the viscosity ratio. So, for example, if the layers are of equal viscosity, the hybridization time is reduced to $\tau_{\mathrm{H}} \sim 4$ days. For an extreme case of viscosity contrast with viscous melt $\left(\sim 10^{7}\right.$ $\mathrm{Pa} \mathrm{s}$ ) above less viscous melt (100 Pa s), the hybridization time is 100 times longer or about $70 \mathrm{yr}$. Of course, in the latter case, if a significant density difference exists between the magmas, dynamically passive mixing is not appropriate and mixing times would be longer. The timescale for hybridization is proportional to $\mathrm{B}^{-1}$ or $\mathrm{B}^{-2}$ depending on prevailing conditions (e.g., Oldenburg et al. 1989; Davaille 1999a, 1999b; Gonnermann et al. 2002).

In conclusion, the mixing times estimated here are consistent with field observations of mixed magmas in volcanic and plutonic environments spanning the range from little to no mixing through various stages of magma mingling observed as incomplete mixing and finally to essentially complete homogenization or magma hybridization at some appropriate scale of scrutiny of order millimeters to centimeters. In the latter case, attainment of thermodynamic equilibration has essentially been reached and the resulting homogeneous magma is identified as hybrid (H) magma. Making the connection between laboratory and numerical studies of magma mixing with quantified examples from the geologic record, using the statistical tools of the scale and intensity of segregation is an important future goal. Attention has focused here on the archetypical case of a layered magma system although nature is certainly more complicated. Regardless of the complexities of the fluid mechanics of magma mixing, in the end-member case of magma hybridization, the state of the hybridized magma can be determined by thermodynamics since the linear scale of segregation and intensity of segregation are small numbers, approaching zero. The thermodynamics of hybridization, valid in the limit $\Lambda=I \rightarrow 0$, is illustrated using an exploratory model in the remainder of this study.

\section{MAGMA HYBRIDIZATION: FORMULATION OF AN EXPLORATORY MODEL}

\section{Introduction}

Magma hybridization represents the end-member limit of magma mixing when thermodynamic equilibrium is attained. Transport phenomena are not relevant in this limit; it is assumed that adequate time has passed to attain a well-mixed equilibrium state. As noted above, the temporal chemical evolution of magma mixing is rather complicated, even in idealized scenarios such as "dense/hot" below "light/cool." Although magma hybridization is an end-member process, much can be learned by study of the thermochemistry of hybridization. To better understand the relationship between the state and properties of the mixing magmas ( $\mathbf{M}$ and $\mathbf{R}$ ) and resultant hybrid $(\mathbf{H})$, an exploratory or "toy" model for magma hybridization based on isobaric binary eutectic phase relations has been developed. This model is used to study the taxonomy of magma hybridization; specifically, how various initial states evolve into one of a few possible final states. In addition, a surprising thermal effect in which the temperature of hybridized magma can be significantly less than either of the mixing magmas is presented and discussed. Calculations based on the Magma Chamber Simulator (Bohrson et al. 2014) are used to verify that this unexpected thermal effect in fact occurs in multicomponent-multiphase systems and is not an artifact of the simplicity of the toy model. Examples of the effects of stoped wholly crystalline blocks and reaction of mushy blocks 
with resident magma are also given. Finally, differences between adiabatic and diabatic hybridization are explored. In essence, the exploratory model can be used to elucidate clearly, without distracting detail, principles of the thermodynamics underlying the process of magma hybridization. These principles are of general applicability and carry over to more compositionally complicated systems.

\section{Toy model description}

The phase diagram isobaric $T X$ section of the exploratory system is depicted in Figure 2. Table 2 identifies all parameters used in the toy model. The toy system is a binary component eutectic phase diagram similar to the system $\mathrm{CaMgSi}_{2} \mathrm{O}_{6}-\mathrm{CaAl}_{2} \mathrm{Si}_{2} \mathrm{O}_{8}$, with no crystalline solution. There are three possible phases in this system: crystals of phase $\alpha$, crystals of phase $\beta$, and a liquid phase. The two components of this system are A and B with $\alpha$ phase pure component $\mathrm{A}$ and phase $\beta$ pure component $\mathrm{B}$. For ease of explanation, and without loss of generality, liquidii are linearized to make the analytical treatment transparent. However, curved liquidii can easily be treated. A few calculations done with curved liquidii, while giving slightly different quantitative solutions, show no large differences. Although thermodynamic parameters relevant to the system $\mathrm{CaMgSi}_{2} \mathrm{O}_{6}-\mathrm{CaAl}_{2} \mathrm{Si}_{2} \mathrm{O}_{8}$ have been used, the point of the exploratory model is to study the principles of hybridization and not to model any particular system. Indeed, the parameters required to define the phase topology and thermodynamics can be changed to study their effects explicitly.

There are eight thermodynamic parameters needed to define (isobarically) the topology of the toy system. These include the eutectic composition, $X_{\mathrm{e}}$, and temperature, $\mathrm{T}_{\mathrm{e}}$, congruent melting temperature of pure $\alpha$ and $\beta$ crystals $\left(T_{\mathrm{m}}^{\alpha}\right.$ and $T_{\mathrm{m}}^{\beta}$ ) and the specific (perunitmass) fusion enthalpies of $\alpha$ and $\beta\left(\Delta \mathrm{h}^{\alpha}, \Delta \mathrm{h}^{\beta}\right)$. The remaining two parameters are isobaric specific heats, one for the solids (i.e., $\alpha$ and $\beta$ crystals), $C_{S}$, and one for the liquid (i.e., melt), $C_{L}$. These

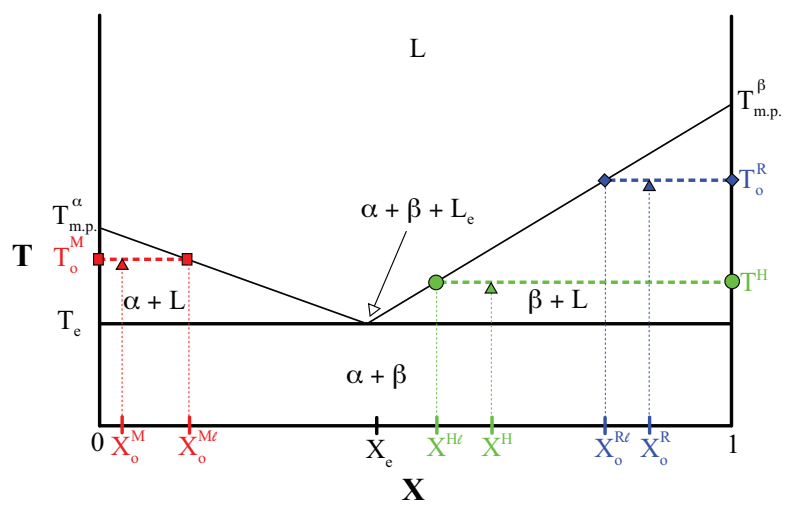

FIGURE 2. Schematic portrayal of phase relations in a typical toy model realization. $\mathbf{M}$ magma (shown in red with square tie-line endpoints) and $\mathbf{R}$ magma (shown in blue with diamond tie-line endpoints), each initially in internal equilibrium, are mixed and allowed to attain equilibrium, producing hybrid magma $\mathbf{H}$ (shown in green with circle tie-line endpoints). In the example depicted, $\mathbf{H}$ magma is saturated in $\beta$ and the associated temperature is less than the initial temperatures of both $\mathbf{M}$ and $\mathbf{R}$. See text for discussion of this anomalous thermal effect. Table 2 provides definitions of all parameters. (Color online.) isobaric specific heats are constant, independent of temperature and composition. This approximation alters quantitative results only slightly and does not substantially affect the conclusions. In fact, at igneous temperatures, the isobaric specific heats of

TABLE 2. Nomenclature and variable definitions for exploratory model

\begin{tabular}{|c|c|}
\hline Quantity & Definition (units) \\
\hline$X$ & Mass fraction component B \\
\hline Y & Mass fraction component $\mathrm{A}$ \\
\hline$X_{\mathrm{e}}$ & Eutectic composition \\
\hline$T_{\mathrm{e}}$ & Eutectic temperature $(\mathrm{K})$ \\
\hline$T_{\text {m.p. }}^{\alpha}$ & Melting point phase $\alpha(\mathrm{K})$ \\
\hline$T_{\text {m.p. }}^{\beta}$ & Melting point phase $\beta(\mathrm{K})$ \\
\hline$\Delta \mathrm{h}^{\alpha}$ & Specific fusion enthalpy phase $\alpha(\mathrm{kJ} / \mathrm{kg})$ \\
\hline$\Delta \mathrm{h}^{\beta}$ & Specific fusion enthalpy phase $\beta(\mathrm{kJ} / \mathrm{kg})$ \\
\hline$C_{s}$ & Isobaric specific heat of solid (J/kg K) \\
\hline$C_{L}$ & Isobaric specific heat of liquid (J/kg K) \\
\hline$\Delta \mathrm{C}$ & $C_{L}-C_{S}(J / k g ~ K)$ \\
\hline$X_{\mathrm{o}}^{\mathrm{M}}$ & Initial mass fraction of component B in $\mathbf{M}$ magma \\
\hline$X_{\mathrm{o}}^{\mathrm{M} 1}$ & Initial mass fraction of component $\mathrm{B}$ in $\mathbf{M}$ magma liquid \\
\hline$X_{\circ}^{\mathrm{R}}$ & Initial mass fraction of component B in $\mathbf{R}$ magma \\
\hline$X_{0}^{\mathrm{R} 1}$ & Initial mass fraction of component $B$ in $\mathbf{R}$ magma liquid \\
\hline$T_{\mathrm{o}}^{\mathrm{M}}$ & Initial $T$ of $\mathbf{M}$ magma $(\mathrm{K})$ \\
\hline$T_{\mathrm{o}}^{\mathrm{R}}$ & Initial $T$ of $\mathbf{R}$ magma (K) \\
\hline$T_{1}^{\mathrm{R}}$ & Liquidus $T$ of $\mathbf{R}$ magma of bulk composition $X_{o(\mathrm{~K})}^{R}$ \\
\hline$T_{1}^{\mathrm{M}}$ & Liquidus $T$ of $\mathbf{M}$ magma of bulk composition $X_{\mathrm{o}}^{\mathrm{M}}(\mathrm{K})$ \\
\hline$X^{H}$ & Mass fraction of component $B$ in hybrid magma \\
\hline$X^{H 1}$ & Mass fraction of component $\mathbf{B}$ in $\mathbf{H}$ magma liquid \\
\hline$T^{H}$ & $T$ of hybrid magma $(\mathrm{K})$ \\
\hline$f_{o}$ & Mass fraction of $\mathbf{M}$ magma \\
\hline$\Re=\frac{f_{o}}{1-f_{o}}$ & Mixing ratio, mass of $\mathbf{M} /$ mass of $\mathbf{R}$ \\
\hline $\mathrm{h}_{\mathrm{L} \alpha}^{\mathrm{M}}$ & $\begin{array}{l}\text { Specific enthalpy } \mathbf{M} \text { magma contributes to hybrid magma } \\
\text { if } \mathbf{M} \text { magma is single phase liquid of bulk composition } \\
\qquad X_{\mathrm{o}}^{\mathrm{M}}<X_{\mathrm{e}}(\mathrm{J} / \mathrm{kg})\end{array}$ \\
\hline $\mathrm{h}_{\mathrm{L} \mathrm{M}}^{\mathrm{M}}$ & $\begin{array}{l}\text { Specific enthalpy } \mathbf{M} \text { magma contributes to hybrid magma } \\
\text { if } \mathbf{M} \text { magma is single phase liquid of bulk composition } \\
\qquad X_{o}^{M}<X_{e}(\mathrm{~J} / \mathrm{kg})\end{array}$ \\
\hline$h_{\alpha+L}^{M}$ & $\begin{array}{l}\text { Specific enthalpy } \mathbf{M} \text { magma contributes to hybrid magma } \\
\text { when } \mathbf{M} \text { magma is } \mathrm{L}+\alpha \text { mixture of bulk composition } \\
\qquad X_{\circ}^{M}<X_{\mathrm{e}}(\mathrm{J} / \mathrm{kg})\end{array}$ \\
\hline$h_{\beta+L}^{M}$ & $\begin{array}{l}\text { Specific enthalpy } \mathbf{M} \text { magma contributes to hybrid magma } \\
\text { when } \mathbf{M} \text { magma is } \mathrm{L}+\beta \text { mixture of bulk composition } \\
\qquad X_{\mathrm{o}}^{\mathrm{M}}<X_{\mathrm{e}}(\mathrm{J} / \mathrm{kg})\end{array}$ \\
\hline $\mathrm{h}_{\alpha+\beta}^{\mathrm{M}}$ & $\begin{array}{c}\text { Specific enthalpy } \mathbf{M} \text { magma contributes to hybrid magma } \\
\text { when } \mathbf{M} \text { magma is } \alpha+\beta \text { crystal mixture }(\mathrm{J} / \mathrm{kg})\end{array}$ \\
\hline $\mathrm{h}_{\llcorner\alpha}^{\mathrm{R}}$ & $\begin{array}{l}\text { Specific enthalpy } \mathbf{R} \text { magma contributes to hybrid magma } \\
\text { when } \mathbf{R} \text { magma is single phase liquid of bulk composition } \\
\qquad X_{\mathrm{o}}^{\mathrm{R}}<X_{\mathrm{e}}(\mathrm{J} / \mathrm{kg})\end{array}$ \\
\hline$h_{L \beta}^{R}$ & $\begin{array}{l}\text { Specific enthalpy } \mathbf{R} \text { magma contributes to hybrid magma } \\
\text { when } \mathbf{R} \text { magma is single phase liquid of bulk composition } \\
\qquad X_{\mathrm{o}}^{\mathrm{R}}<X_{\mathrm{e}}(\mathrm{J} / \mathrm{kg})\end{array}$ \\
\hline$h_{\alpha+L}^{R}$ & $\begin{array}{l}\text { Specific enthalpy } \mathbf{R} \text { magma contributes to hybrid magma } \\
\text { when } \mathbf{R} \text { magma is } \mathrm{L}+\alpha \text { mixture of bulk composition } \\
\qquad X_{\mathrm{o}}^{\mathrm{M}}<X_{\mathrm{e}}(\mathrm{J} / \mathrm{kg})\end{array}$ \\
\hline$h_{\beta+L}^{R}$ & $\begin{array}{l}\text { Specific enthalpy } \mathbf{R} \text { magma contributes to hybrid magma } \\
\text { when } \mathbf{R} \text { magma is } L+\beta \text { mixture of bulk composition } \\
\qquad X_{0}^{M}<X_{\mathrm{e}}(\mathrm{J} / \mathrm{kg})\end{array}$ \\
\hline$h_{\alpha+\beta}^{R}$ & $\begin{array}{c}\text { Specific enthalpy } \mathbf{R} \text { magma contributes to hybrid magma } \\
\text { when } \mathbf{R} \text { magma is } \alpha+\beta \text { crystal mixture }(\mathrm{J} / \mathrm{kg})\end{array}$ \\
\hline $\mathrm{h}_{\max }$ & $\begin{array}{l}\text { Specific enthalpy value at boundary between } \\
\qquad \mathrm{L} \text { and } \alpha+\mathrm{L} \text { or } \beta+\mathrm{L} \text { field }(\mathrm{J} / \mathrm{kg})\end{array}$ \\
\hline mid & $\begin{array}{l}\text { Specific enthalpy value at boundary between } \\
\qquad \alpha+L \text { or } \beta+L \text { and } L_{e}+\alpha+\beta(\mathrm{J} / \mathrm{kg})\end{array}$ \\
\hline $\mathrm{h}_{\min }$ & $\begin{array}{l}\text { Specific enthalpy value at boundary between } \\
\qquad \mathrm{L}_{\mathrm{e}}+\alpha+\beta \text { and } \alpha+\beta \text { field }(\mathrm{J} / \mathrm{kg})\end{array}$ \\
\hline $\mathrm{h}_{\mathrm{GMAX}}$ & $\begin{array}{c}\text { Maximum possible initial specific enthalpy for } \mathbf{M}+\mathbf{R} \text { in } \\
\text { Monte Carlo realizations }(\mathrm{J} / \mathrm{kg})\end{array}$ \\
\hline $\mathrm{h}_{\text {GMIN }}$ & $\begin{array}{c}\text { Minimum possible initial specific enthalpy for } \mathbf{M}+\mathbf{R} \text { in } \\
\text { Monte Carlo realizations }(\mathrm{J} / \mathrm{kg})\end{array}$ \\
\hline$\Phi$ & $\begin{array}{l}\text { Ratio of initial } \mathbf{M}+\mathbf{R} \text { specific enthalpy (suitably weighted) } \\
\text { to the specific enthalpy of the hybrid magma } \mathbf{H}: \mathrm{h}^{\mathrm{H}}=\Phi\left(\mathrm{h}^{\mathrm{M}}+\mathrm{h}^{\mathrm{R}}\right)\end{array}$ \\
\hline$W_{1}^{\prime}$ & $\begin{array}{c}\text { Mass fraction of } \mathrm{I}^{\text {th }} \text { phase }\left(\alpha, \beta \text {, or I) in } \mathrm{J}^{\text {th }} \text { subsystem }\right. \\
(\mathbf{M}, \mathbf{R}, \text { or } \mathbf{H})\end{array}$ \\
\hline
\end{tabular}


liquids and crystals vary little with temperature and composition, especially when the ranges of $X$ and $T$ are small. In the toy model, heats of mixing associated with non-ideality are neglected. Although mixing enthalpies are generally not identically zero, they are relatively small compared to fusion enthalpies and, when translated into temperature differences, are of order 10-40 K. For example, in the system $\mathrm{CaMgSi}_{2} \mathrm{O}_{6}-\mathrm{CaAl}_{2} \mathrm{Si}_{2} \mathrm{O}_{8}$ the maximum excess enthalpy associated with mixing is $\sim 60 \mathrm{~kJ} / \mathrm{kg}$ (Sugawara and Akaogi 2003). In comparison, the fusion enthalpies of diopside and anorthite are 636 and $478 \mathrm{~kJ} / \mathrm{kg}$, respectively, $\sim 10$ times larger. The maximum excess enthalpy (heat of mixing) couched in terms of a temperature difference is $\sim 30 \mathrm{~K}$. Because the exploratory model is not meant to be representative of any natural system but rather a tool to study the thermochemical principles of hybridization, these limitations do not impact its implications for natural systems.

In addition to the eight thermodynamic parameters required to define the phase diagram and mixing energetics, six additional parameters are needed to initialize the system and uniquely compute the state of hybrid magma $(\mathbf{H})$ when $\mathbf{M}$ and $\mathbf{R}$ magmas completely mix to attain a hybrid state with $I \rightarrow 0$ and $\Lambda \rightarrow 0$. These parameters are: the initial temperatures $\left(T_{\mathrm{o}}^{\mathrm{M}}, T_{\mathrm{o}}^{\mathrm{R}}\right)$ and bulk compositions $\left(X_{\mathrm{o}}^{\mathrm{M}}, X^{\mathrm{R}}\right)$ of $\mathbf{M}$ and $\mathbf{R}$, the mass fraction of $\mathbf{M}$ magma $\left(f_{o}\right)$ in the $\mathbf{M}+\mathbf{R}$ mixture, and $\Phi$, the ratio of the specific enthalpy of the initial enthalpy sum $(\mathbf{M}+\mathbf{R})$ to hybrid $(\mathbf{H})$ enthalpy (see below). An alternative parameter, the mixing ratio defined as $\mathfrak{R}$ $=($ mass of $\mathbf{M}) /($ mass of $\mathbf{R})$ where $\Re=f_{0} /\left(1-f_{0}\right)$ can also be used to describe the relative masses of the mixing magmas.

The toy model can handle both adiabatic (isenthalpic) and diabatic magma hybridization. Adiabatic mixing is for recharge treated as an isenthalpic process. Because isenthalpic or Rhybridization is closed (no mass exchange with environment, only homogenization of $\mathbf{M}$ and $\mathbf{R}$ ) and adiabatic, the bulk composition of hybrid magma $\left(X^{\mathrm{H}}\right)$ and its specific enthalpy $\left(\mathrm{h}^{\mathrm{H}}\right)$ are identical to the initial bulk composition and specific enthalpy of $\mathbf{M}+\mathbf{R}$ appropriately mass-weighted according to the mixing ratio. The requirement of thermodynamic equilibrium enables determination of the temperature $\left(T^{\mathrm{H}}\right)$, bulk composition $\left(X^{\mathrm{H}}\right)$ and phase assemblage (mass fractions, $\mathrm{w}_{\alpha}^{\mathrm{H}}, \mathrm{w}_{\beta}^{\mathrm{H}}$, and $\mathrm{w}_{1}^{\mathrm{H}}$ ) and melt composition, $X^{\mathrm{H} 1}$ of hybridized magma. Diabatic hybridization involves simultaneous recharge and crystallization. Again, the system is closed with respect to mass but the final enthalpy of the hybrid magma is set equal to some fraction $\Phi$ of the $\mathbf{M}+\mathbf{R}$ weighted specific enthalpy according to $\mathrm{h}^{\mathrm{H}}=\Phi \mathrm{h}_{\mathrm{o}}^{\mathrm{M}+\mathrm{R}}$ where $0<$ $\Phi<1$. By definition, $\Phi=1$ corresponds to R-hybridization since no loss of heat to the environment occurs. The diabatic parameter $\Phi$ is specified upon initialization of the calculation, where $1-\Phi$ is the fraction of heat (fraction of initial $\mathbf{M}+\mathbf{R}$ enthalpy) that is lost to the surroundings during the recharge event. This "lost" heat triggers crystallization above and beyond what occurs in isenthalpic (adiabatic) R-hybridization, and this process is therefore termed RFC-hybridization. It is noted that equilibrium and fractional crystallization produce identical compositional effects in binary eutectic systems. The thermodynamic potential that is maximized in R-hybridization in the entropy (Tisza 1977). Minimization of the Gibbs energy is not the appropriate action in isobaric, fixed enthalpy R-hybridization. In this study, the eight thermodynamic parameters that define the phase diagram independent of initial conditions are fixed at single values to focus specifically on effects of initial conditions rather than thermodynamic properties.

In summary, once phase diagram topology is fixed, specification of the temperature, bulk composition and mixing ratio of $\mathbf{M}$ and $\mathbf{R}$ allows the temperature, bulk composition and phase assemblage and melt composition of hybrid magma to be computed for a given value of the diabatic parameter. For $\Phi=1$, the solution corresponds to isenthalpic R-hybridization whereas for $0<\Phi<1$ the mixing scenario corresponds to diabatic RFC-hybridization. Figure 2 schematically depicts a typical R-hybridization result based upon a phase diagram topology similar to the system $\mathrm{CaMgSi}_{2} \mathrm{O}_{6}-\mathrm{CaAl}_{2} \mathrm{Si}_{2} \mathrm{O}_{8}$ at $10^{-4} \mathrm{GPa}$. In this example, $\alpha$-phyric $\mathbf{M}$ magma is mixed with $\beta$-phyric $\mathbf{R}$ magma to produce a hybrid magma saturated in $\beta$ at the final post-mixing temperature $T^{\mathrm{H}}$. By analogy with the system $\mathrm{CaMgSi}_{2} \mathrm{O}_{6}-\mathrm{CaAl}_{2} \mathrm{Si}_{2} \mathrm{O}_{8}, \beta$ can be identified with anorthite and $\alpha$ with diopside and $X_{\mathrm{B}}$ refers to the mass fraction of $\mathrm{CaAl}_{2} \mathrm{Si}_{2} \mathrm{O}_{8}$ component. A complete description and thermodynamic derivation of the toy model is given in Appendix $\mathrm{A}^{1}$. A downloadable spreadsheet that fully implements the toy model is available at http://magma.geol.ucsb.edu/index. $\mathrm{html}$. Insights gained from analysis of the toy model pertaining to the thermodynamics of magma hybridization are discussed in the following sections.

\section{RESULTS OF APPLICATION OF TOY MODEL TO PETROLOGIC PROBLEMS}

Below, the toy model is used to examine a range of problems associated with the thermodynamics of magma hybridization. The main goal is to examine scenarios that are of potential wide application to natural systems. We show that even though the model is simple, the principles carry over to magma mixing in multiphase-multicomponent natural systems.

\section{Probability distribution of outcomes: Monte Carlo simulation and a thermodynamic attractor}

Regardless of initial conditions, the phase state of hybrid magma (i.e., post mixing and equilibration) corresponds to one of five possibilities: $\mathrm{L}, \alpha+\mathrm{L}$ (if $X^{\mathrm{H}}<X_{\mathrm{e}}$ ), $\beta+\mathrm{L}$ (if $X^{\mathrm{H}}>X_{\mathrm{e}}$ ), $\mathrm{L}_{\mathrm{e}}+\alpha+\beta$ or $\alpha+\beta$, where $\mathrm{L}_{\mathrm{e}}$ is melt of eutectic composition. It is informative to study the probability distribution of phase state outcomes for R-hybridization. Specifically, for fixed magma thermodynamic properties and phase relations, given a reasonable range of initial values $\left(T_{\mathrm{o}}^{\mathrm{M}}, T_{\mathrm{o}}^{\mathrm{R}}, T_{\mathrm{o}}^{\mathrm{M}}, T_{\mathrm{o}}^{\mathrm{R}}, \mathrm{f}_{\mathrm{o}}^{\mathrm{M}}\right)$ describing $\mathbf{M}$ and $\mathbf{R}$, is any particular phase assemblage outcome of the five possibilities more probable than any other? If there is not a stochastic (random) distribution of outcomes, what is the thermodynamic principle behind the outcome probability distribution? This question is addressed by Monte Carlo (MC) simulation and by analysis using the thermodynamic parameters and phase diagram. The conclusion is that the invariant assemblage outcome of eutectic melt coexisting with crystals of $\alpha$ and $\beta\left(\mathrm{L}_{\mathrm{e}}+\alpha+\beta\right)$ occurs significantly more frequently than other outcomes. Thus, we conclude that the invariant point acts as a "thermodynamic attractor." The thermodynamic explanation of why this occurs is given below

${ }^{2}$ Deposit item AM-16-35305, Appendix and Tables. Deposit items are free to all readers and found on the MSA web site, via the specific issue's Table of Contents (go to http://www.minsocam.org/MSA/AmMin/TOC/). 
after MC results are presented.

The Monte Carlo approach requires defining input distributions for each of the five initial conditions on $\mathbf{M}$ and $\mathbf{R}$. The range and population distribution statistics for each variable is given in Table 3. An MC simulation is undertaken by random selection of a particular value for each of the five initial condition parameters. This single value is randomly chosen from the range defined $a b$ initio. Once individual values of each required parameter are selected, a toy model calculation is performed to generate the final hybrid magma state. Statistical analysis of 5.3 million MC simulations, based on the initial condition distributions of Table 3, gives the following for the phase assemblage distribution of $\mathbf{H}$ magma: $\mathrm{L}(6.5 \%), \alpha+\mathrm{L}(11.3 \%), \beta+\mathrm{L}(18.5 \%), \mathrm{L}_{\mathrm{e}}+\alpha+\beta(44 \%)$, and $\alpha+\beta(23 \%)$. Since $X_{\mathrm{e}}(=0.42)$ is $<0.5$ and the initial distributions for $X^{\mathrm{M}}$ and $X^{\mathrm{R}}$ are symmetric around 0.5 by choice, one expects, simply on compositional grounds, more $\mathrm{L}+\beta$ than $\mathrm{L}+\alpha$ outcomes. Indeed this is noted in the MC results (18\% vs. 11\%). Similarly, because highly superheated melts, those with temperature above the melting points of $\alpha$ and $\beta$ crystals, are avoided by choice in the initial $T^{\mathrm{M}}$ and $T^{\mathrm{R}}$ distributions, one expects more sub-solidus $\alpha+\beta$ outcomes than hyper liquidus L outcomes. This expectation is also reflected in the results $(23 \%$ vs. $7 \%)$. One feature of the results is not easily rationalized from the initial distributions and phase diagram topology: the relatively large fraction of hybrid states $(\sim 44 \%)$ at the invariant point condition of $T=T_{\mathrm{e}}$, with phase assemblage $\mathrm{L}_{\mathrm{e}}+\alpha+\beta$. That is, nearly half of all outcomes (44\%) are invariant point outcomes in which three phases $\left(\mathrm{L}_{\mathrm{e}}+\alpha+\beta\right)$ coexist at the final hybrid magma temperature $T^{\mathrm{H}}=T_{\mathrm{e}}$. We have performed MC simulations for many other initial condition ranges and for systems with different fusion enthalpies and melting points and heat capacities and this phenomenon - a disproportionate number of invariant point outcomes - is consistently found. From these observations, we conclude that the invariant point acts as a thermodynamic "attractor."

The thermodynamic basis of this feature can be appreciated by examination of Figure 3. This diagram of temperature vs. enthalpy of hybrid magma, $\mathrm{h}^{\mathrm{H}}$ pertains to an arbitrary but fixed bulk composition $X^{\mathrm{H}}$. The possible stable phase assemblages for this bulk composition are separated by critical values of the enthalpy. For example, $\mathrm{h}_{\max }$ separates the $\mathrm{L}$ field from the $\mathrm{L}+\alpha$ (or, if $X^{\mathrm{H}}>X_{\mathrm{e}}, \mathrm{L}+\beta$ ) field. If $\mathrm{h}^{\mathrm{H}}>\mathrm{h}_{\max }$, then the hybrid temperature consistent with the enthalpy of the initial state exceeds the liquidus temperature of bulk composition $X^{\mathrm{H}}$ and the final state is all $\mathrm{L}$ of composition $X=X^{\mathrm{H}} \cdot \mathrm{h}_{\max }$ is thus the maximum value of the enthalpy such that the stable assemblage include crystals of $\alpha($ or $\beta)$. Similarly, when hybrid magma has a specific enthalpy between $h_{\text {mid }}$ and $h_{\text {min }}$, hybrid magma will be the three-phase mixture of eutectic melt, $\alpha$ and $\beta$ crystals $\left(\mathrm{L}_{\mathrm{e}}+\alpha+\beta\right)$. It is noted that for the particular composition $X^{\mathrm{H}}, \mathrm{h}_{\mathrm{GMIN}}$, and $\mathrm{h}_{\mathrm{GMAX}}$ are the absolute minimum and maximum (hence "global") values for the enthalpy consistent with the initial condition extremes of Table 3 and the specific bulk composition $X=X^{\mathrm{H}}$. The significance of Figure 3 is that outcome probabilities can be predicted because the probability of a given phase assemblage outcome is proportional to the enthalpy fraction associated with that particular assemblage. For example, the probability of invariant point assemblage outcome is proportional to the fraction $\left(\mathrm{h}_{\text {mid }}-\mathrm{h}_{\min }\right) /$ $\left(\mathrm{h}_{\mathrm{GMAX}}-\mathrm{h}_{\mathrm{GMIN}}\right)$. The relatively large enthalpy interval, from $\mathrm{h}_{\text {mid }}$ to $h_{\min }$ portrayed in Figure 3 therefore implies that a relatively large portion of outcomes will be three-phase invariant point outcomes. The enthalpy range is large because of the latent heat effect associated with crystallization of crystalline phases $\alpha$ and $\beta$. Hence, the basis for the invariant point attractor is enthalpic. To summarize, there is a wide range of system enthalpies consistent with an invariant point assemblage due to the heat sink associated with crystallization effects. It is therefore expected that when crystallizing, systems remain at or near these locations in $T-X$ space when magmas are mixed and hybridized.

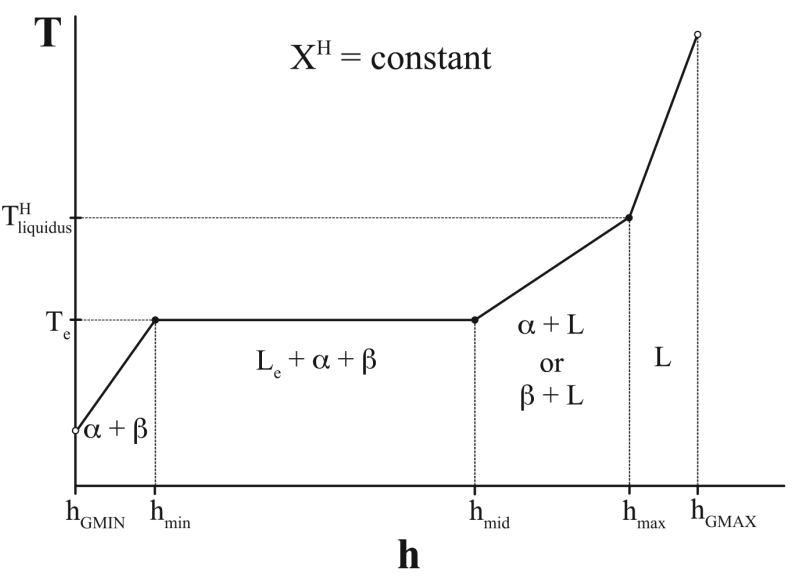

FIGURE 3. Relationship between temperature and specific enthalpy for fixed composition of $\mathbf{H}$ magma. Each possible phase assemblage of $\mathbf{H}$ magma occupies a distinct region in temperature-specific enthalpy (h) coordinates. The relatively wide enthalpy range $\mathrm{h}_{\text {mid }}-\mathrm{h}_{\text {min }}$ associated with the invariant point assemblage $L_{\mathrm{e}}+\alpha+\beta$, where $L_{\mathrm{e}}$ is melt of eutectic composition, is the basis of the thermodynamic "attractor" effect. The open circles labeled $\mathrm{h}_{\mathrm{GMIN}}$ and $\mathrm{h}_{\mathrm{GMAX}}$ are the absolute minimum and maximum specific enthalpies, respectively, of the system defined by the reasonable but arbitrary initial conditions of Table 3 and are not of special thermodynamic significance unlike $\mathrm{h}_{\min }, \mathrm{h}_{\operatorname{mid}}$, and $\mathrm{h}_{\max }$, which do have special thermodynamic significance: they are the specific enthalpy values that uniquely separate possible phase assemblages.

TABLE 3. Initial condition values for Monte Carlo simulations

\begin{tabular}{|c|c|c|c|c|}
\hline Variable & Mean value & $1 \sigma$ & Absolute minimum value & Absolute maximum value \\
\hline$X_{\mathrm{o}}^{\mathrm{M}}$ & 0.5 & 0.3 & $>0$ & $<1$ \\
\hline$X_{0}^{\mathrm{M}}$ & 0.5 & 0.3 & $>0$ & $<1$ \\
\hline$T_{\circ}^{\mathrm{R}}$ & If $X_{o}^{R}<X_{\mathrm{e},}$ mean value is average of $T_{\text {m.p. }}^{\alpha}$ and $0.98 T_{\mathrm{e}}$ & 150 & $0.98 T_{\mathrm{e}}$ & $T_{\text {m.p. }}^{\alpha}$ \\
\hline$T_{\mathrm{o}}^{\mathrm{R}}$ & If $X_{\mathrm{o}}^{\mathrm{R}}>X_{\mathrm{e}}$ mean is average of $T_{\text {m.p. }}^{\mathrm{B}}$ and $0.98 T_{\mathrm{e}}$ & 150 & $0.98 T_{\mathrm{e}}$ & $T_{\text {m.p. }}^{\beta}$ \\
\hline$T_{\circ}^{\mathrm{M}}$ & If $X_{\mathrm{o}}^{\mathrm{M}}<X_{\mathrm{e}}$, then mean is average of $T_{\text {m.p. }}^{\alpha}$ and $0.98 T_{\mathrm{e}}$ & 150 & $0.98 T_{\mathrm{e}}$ & $T_{\text {m.p. }}^{\alpha}$ \\
\hline$T_{\mathrm{o}}^{\mathrm{M}}$ & If $X_{\mathrm{o}}^{\mathrm{M}}>X_{\mathrm{e}}$, mean is average of $T_{\mathrm{m} . p .}^{\mathrm{s}}$ and $0.98 T_{\mathrm{e}}$ & 150 & $0.98 T_{\mathrm{e}}$ & $T_{\text {m.p. }}^{\beta}$ \\
\hline$f_{0}$ & 0.5 & 0.3 & $>0$ & $<1$ \\
\hline
\end{tabular}




\section{Invariant point outcomes: A specific example and application to natural systems}

As noted, a disproportionate fraction of outcomes are threephase invariant point ones in which eutectic liquid $\left(\mathrm{L}_{\mathrm{e}}\right)$ stably coexists with $\alpha$ and $\beta$ crystals. A specific example is illustrated in Figure 4 . M magma $(87 \%$ melt $+12 \% \beta$, identified by square tie-line endpoints at $T^{\mathrm{M}}=1580 \mathrm{~K}$ is mixed with $\mathbf{R}$ magma ( $75 \%$ melt $+25 \% \alpha$, identified by diamond tie-line endpoints) initially at $T^{\mathrm{R}}=1620 \mathrm{~K}$. The fraction of $\mathbf{M}$ in the mixture is $\mathrm{f}_{\mathrm{o}}=0.7$, equivalent to a mixing ratio of 2.33 . Hybridized $\mathbf{H}$ magma, identified by circle tie-line endpoints, is invariant point magma with $98 \%$ melt of eutectic composition, $1.1 \% \alpha$, and $1 \% \beta$ crystals by mass.

The thermodynamic attractor concept is relevant to more complex multicomponent-multiphase systems because the enthalpic roots of its origin apply to multiphase-multicomponent systems, not just binary eutectic systems. The essential feature is that by virtue of the large difference in enthalpy between a liquid and solid of identical bulk composition, the invariant point state is consistent with a wide range of system specific (per unit mass) enthalpy values. Although in multicomponent systems invariant points are less common than in a simple binary system, a consequence of the phase rule, multicomponent-multiphase systems do nevertheless possess locations of low-thermodynamic variance in temperatureenthalpy-composition space. These low-variance states serve as multicomponent thermodynamic "attractors" via the enthalpic effect. Two natural systems come to mind where invariant points may control melt compositions in RFC systems. One is the prototypical mantle system involving the ternary eutectic assemblage $\mathrm{L}+$ olivine + clinopyroxene + plagioclase in the shallow mantle and the assemblage $\mathrm{L}+$ olivine + clinopyroxene + garnet relevant to the deeper upper mantle. A second is the granite ternary system of quartz + alkali feldspar + plagioclase where the ternary minimum is a pseudo-invariant point. The fact that these two systems are relevant to magma crystallization

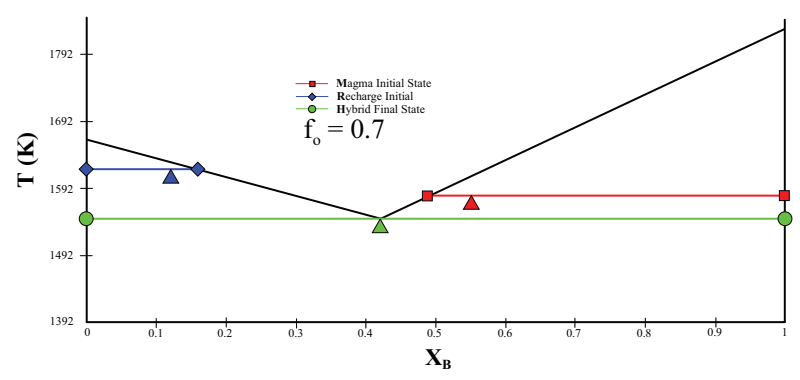

FIGURE 4. Illustration of thermodynamic "attractor" effect. Crystal laden $\mathbf{M}\left(87 \%\right.$ melt $+12 \% \beta$ initally at $\left.T^{\mathrm{M}}=1580 \mathrm{~K}\right)$ and $\mathbf{R}(75 \%$ melt + $25 \% \alpha$ initially at $T^{\mathrm{R}}=1620 \mathrm{~K}$ ) magmas hybridize producing magma $\mathbf{H}$. The fraction of $\mathbf{M}$ in the mixture is $\mathrm{f}_{\mathrm{o}}=0.7$, equivalent to a mass mixing ratio of $\mathbf{M}$ to $\mathbf{R}$ magma of $\Re=2.3$. It is noted that $T^{\mathrm{H}}$ is less than both $T^{\mathrm{M}}$ and $T^{\mathrm{R}}$ [the act of magma hybridization produces a cooler resultant magma $(\mathbf{H})$ than either end-member $\mathbf{M}$ or $\mathbf{R}]$ and $\mathrm{H}$ is multiply saturated $(\alpha+\beta)$ with coexisting melt of eutectic composition, Le. The enthalpy of $\mathbf{H}$ is identical to the mass weighted sum of $\mathbf{M}$ and $\mathbf{R}$ enthalpies ( $\Phi=1)$ in this example of R-hybridization. (Color online.) fundamental to the generation of oceanic crust and continental crust, respectively, suggests that the petrologic "attractor" is relevant to mantle and crustal petrology.

\section{Melt vs. magma hybridization}

When resident magma $(\mathbf{M})$ and recharge magma $(\mathbf{R})$ are crystal-liquid mixtures, hybridization outcomes can be quite different than the case when two liquids are homogenized to give a third liquid. Below, we first present the (trivial) case of homogenization of two melts to give a third homogeneous melt. This is followed by contrasting cases that describe outcomes when magmas, not melts, are mixed. These cases highlight the differences between melt mixing and magma mixing, reveal characteristics of mixed systems that have not been previously emphasized, and show the potential that the exploratory toy model have for providing explanations for the characteristics of particular petrologic systems.

\section{Hybridization of melts}

A degenerate application of the toy model is the state of hybrid product when two melts of distinct temperature and compositions hybridize isenthalpically (R-hybridization). It can be shown from the expressions in Appendix Tables $1^{1}$ and $2^{1}$ that if $\mathbf{M}$ and $\mathbf{R}$ are all liquid (or just saturated at their respective liquidus temperatures), then the resulting hybrid is also a single phase melt (or just saturated). The temperature and composition of hybridized melt are

$$
\begin{aligned}
X^{\mathrm{H}} & =\mathrm{f}_{\mathrm{o}} X_{\mathrm{o}}^{\mathrm{M}}+\left(1-\mathrm{f}_{\mathrm{o}}\right) X_{\mathrm{o}}^{\mathrm{R}} \\
T^{\mathrm{H}} & =\mathrm{f}_{\mathrm{o}} T_{\mathrm{o}}^{\mathrm{M}}+\left(1-\mathrm{f}_{\mathrm{o}}\right) T_{\mathrm{o}}^{\mathrm{R}} .
\end{aligned}
$$

That is, the bulk composition and temperature of hybrid melt corresponds to weighted linear mixing. In general, Equation 6 is always correct; Equation 7 is valid strictly when the heat of mixing is identically zero (ideal mixing) as assumed in the toy model. Otherwise, a small modification to account for the heat released (negative heat of mixing) or absorbed (positive heat of mixing) upon the mixing of $\mathbf{M}$ and $\mathbf{R}$ is required. In real systems, this effect is generally rather small. The results of Equations 6 and 7 should be contrasted with the example below that pertains to the mixing and hybridization of magmas.

\section{Anomalous thermal effect}

Intuition suggests that when magmas mix, the temperature of the hybrid product will always lie between the temperatures of the starting magmas, $\mathbf{M}$ and $\mathbf{R}$ as given by Equation 7. That is, $T^{\mathrm{H}} \in\left[T^{\mathrm{M}}, T^{\mathrm{R}}\right]$ in the notation of the toy model. Although true when two compositionally distinct melts mix to form a hybrid melt (as shown above), this is not necessarily the case when magmas mix. An example is illustrated in Figure 5a. $\mathbf{R}$ magma $(80 \%$ melt $+20 \% \beta$ crystals $)$ at initial temperature $T_{\mathrm{o}}^{\mathrm{R}}=1750$ $\mathrm{K}$ is mixed into $\mathbf{M}$ magma (79\% melt $+21 \% \alpha$ crystals) at $T_{\mathrm{o}}^{\mathrm{M}}$ $=1612 \mathrm{~K}$ and hybridized. Hybrid magma is sparsely phyric $(96 \%$ melt $+4 \% \alpha)$ but most significantly the temperature of hybrid magma $T^{\mathrm{H}}$ is $1579 \mathrm{~K}$, which is $170^{\circ}<\mathrm{T}_{\mathrm{o}}^{\mathrm{R}}$ and $33^{\circ}<T_{\mathrm{o}}^{\mathrm{M}}$. This is a surprising result until one realizes that temperature and specific enthalpy do not share a one-to-one relationship in an equilibrium mixture of crystals plus melt. It is the enthalpy 

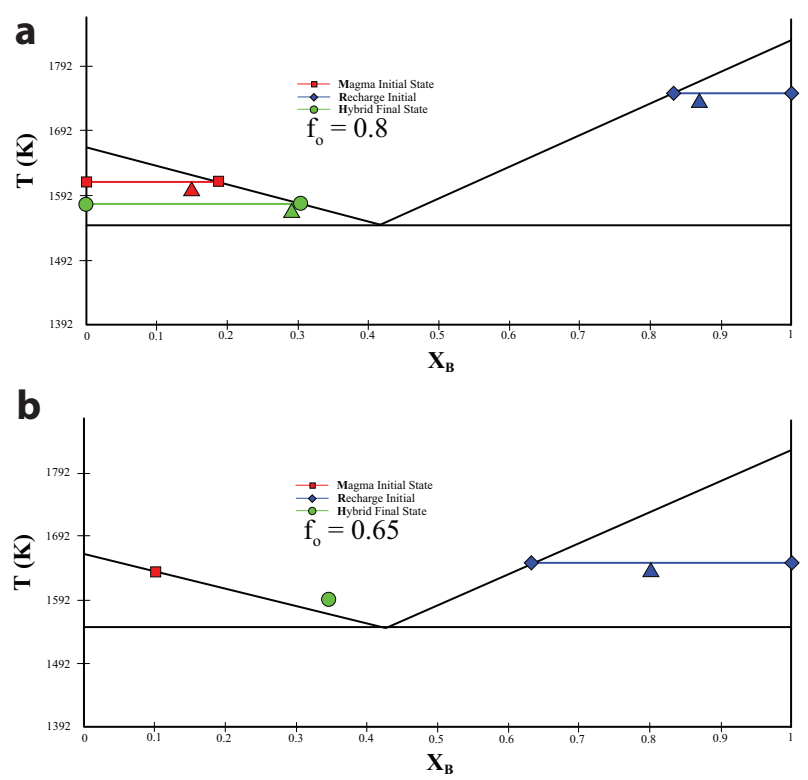

FIGURE 5. Illustration of the anomalous thermal effect. Blue diamonds represent characteristics of recharge melt and solid and triangle represents its bulk composition. (a) $\mathbf{R}$ magma ( $80 \%$ melt $+20 \% \beta$ crystals) at initial temperature $T_{0}^{\mathrm{R}}=1750 \mathrm{~K}$ is hybridized with $\mathbf{M}$ magma $(79 \%$ melt $+21 \%$ $\alpha$ crystals, represented by red squares at tie-line endpoints and triangle fulcrum indicating bulk composition) at $T_{\mathrm{o}}^{\mathrm{M}}=1612 \mathrm{~K}$. The temperature of hybrid magma $\mathbf{H}$ is less than either the initial temperatures of $\mathbf{M}$ or $\mathbf{R}$. The enthalpy of $\mathbf{H}$ is identical to the mass weighted sum of $\mathbf{M}$ and $\mathbf{R}$ enthalpies. (b) $\mathbf{M}$ melt at its liquidus temperature (1636 K) is hybridized with crystal-laden $\mathbf{R}$ magma ( $46 \% \beta$ crystals $+54 \%$ melt, $1650 \mathrm{~K})$. The hybrid magma $\mathbf{H}$ is in the all-liquid region of $T X$ space at a temperature less than either the initial temperatures of $\mathbf{M}$ or $\mathbf{R}$. The enthalpy of $\mathbf{H}$ is identical to the mass weighted sum of $\mathbf{M}$ and $\mathbf{R}$ enthalpies. (Color online.)

that is constant during R-hybridization; temperature is the result of the isenthalpic constraint on mixing. The temperature of hybridized magma follows from an enthalpy balance that includes sensible and latent heat effects in both $\mathbf{M}$ and $\mathbf{R}$. In the example shown in Figure 5a, the fraction of melt in $\mathbf{H}$ is greater than the corresponding melt fractions in $\mathbf{M}$ and $\mathbf{R}$, and yet the temperature of $\mathbf{H}$ is lower because, relative to solid, silicate liquid has a higher specific enthalpy and specific heat capacity. In Figure 5b, an additional example is presented where M lies on its liquidus at $1636 \mathrm{~K}$ where it is just saturated in $\alpha$ and $\mathbf{R}$ is $46 \% \beta$ crystals $+54 \%$ melt at $T_{\mathrm{o}}^{\mathrm{R}}$ of $1650 \mathrm{~K}$. The resultant hybrid magma is crystal-free at $1598 \mathrm{~K}$, which, again, is less than both $T_{\mathrm{o}}^{\mathrm{M}}$ and $T_{\mathrm{o}}^{\mathrm{R}}$. Additional toy model solutions (not shown) enable one to explicitly correlate magnitude of the anomalous thermal effect with the crystal content of $\mathbf{R}$ and M. The magnitude of the thermal effect can be up to $\sim 100 \mathrm{~K}$ for reasonable choices of initial conditions. This "anomalous" thermal effect is therefore a robust and common outcome of magma hybridization in the toy model. Petrographically, this would be reflected in crystal resorption if earlier-formed hightemperature phenocrysts were no longer stable at the lower temperature of the hybridized magma.

The possibility of mixing hot recharge $\mathbf{R}$ melt into warm resident magma $\mathbf{M}$ and ending up with hybridized magma significantly cooler than either is not widely recognized. To investigate this phenomenon further, we have used the Magma Chamber Simulator (MCS) described by Bohrson et al. (2014) to evaluate if this phenomenon continues to be quantitatively significant in multicomponent-multiphase scenarios of isenthalpic R-hybridization. In the MCS, the thermodynamic simplifications of the toy model are not invoked. Hence, one may determine if the anomalous thermal effect applies to more realistic multicomponent-multiphase systems characterized by non-ideality in the melt and crystalline solutions, temperatureand pressure-dependent properties, and the incorporation of $\mathrm{H}_{2} \mathrm{O}$ and oxygen buffers and other ingredients beyond the scope of the toy model. These capabilities are, of course, missing from the exploratory toy model by intent.

Details of a relevant example are given in Table 4. Resident magma $\mathbf{M}$ of crystallinity $43 \%$ (clinopyroxene $\sim 17 \%$, plagioclase $\sim 10 \%$, spinel $\sim 9 \%$, and olivine $\sim 7 \%$ by mass) and basaltic melt composition $\left(51.2 \mathrm{wt} \% \mathrm{SiO}_{2}, 7.2 \mathrm{wt} \% \mathrm{MgO}\right.$, $\left.0.6 \mathrm{wt} \% \mathrm{H}_{2} \mathrm{O}\right)$ at $1458 \mathrm{~K}$ is mixed with basaltic melt $\mathbf{R}$ that is more magnesian and somewhat wetter $(7.7 \mathrm{wt} \% \mathrm{MgO}, 2.6 \mathrm{wt} \%$ $\mathrm{H}_{2} \mathrm{O}$ ) also at $\sim 1458 \mathrm{~K}$. $\mathbf{R}$ magma is at its liquidus temperature and olivine is the liquidus phase. The mixing ratio is $1.11\left(\mathrm{f}_{\mathrm{o}}\right.$ $=0.53$ ); thus, roughly equal amounts of $\mathbf{M}$ and $\mathbf{R}$ are mixed and hybridized. The resulting $\mathbf{H}$ magma has a crystal content of $\sim 13 \mathrm{wt} \%$ (olivine $\sim 6 \%$, spinel $\sim 5 \%$, and clinopyroxene $\sim 2 \%$ by mass) and a temperature of $\sim 1425 \mathrm{~K}$. That is, $T^{\mathrm{H}}$ is $\sim 28 \mathrm{~K}$ lower than the initial temperatures of both $\mathbf{M}$ and $\mathbf{R}$ of $1458 \mathrm{~K}$. Interesting effects are also noted for the composition of hybrid melt, which is more aluminous and calcic yet poorer in $\mathrm{FeO}$ compared to melt in $\mathbf{M}$ and $\mathbf{R}$. All plagioclase from $\mathbf{M}$ has been resorbed, leaving no trace in $\mathbf{H}$ magma. Several additional MCS calculations were done to quantify the relationship between the initial crystal content of $\mathbf{M}$ and the magnitude of the anomalous thermal effect. The results show that there is $\sim-0.8 \mathrm{~K}$ change in hybrid magma temperature for every percent increase in the crystal content of $\mathbf{M}$ magma. The conclusion is that the anomalous cooling effect is not an artifact of toy model simplifications: the effect is real in the hybridization limit of magma mixing and might be expected to occur in nature. The basis of the effect is found, as outlined earlier, in the enthalpy buffering capacity of crystals. Phases with high specific (per unit mass) fusion enthalpies will be more effective in producing anomalous cooling effects. This effect should be a somewhat common effect when crystal-bearing magmas are mixed and allowed to hybridize; indicators of cooling upon mixing should be sought in the rock record. In addition, resorption is a consequence of this type of mixing. Thus disequilibrium textures indicative of resorption may originate not only from an increase in magma temperature but also a decrease. The practical importance of the anomalous thermal effect with respect to geothermometry and interpretation of common disequilibrium textures in magmatic systems remains to be more fully explored.

\section{Digestion of stoped blocks}

The toy model also allows one to investigate the thermodynamics of assimilation, which can be viewed as sub-solidus or "cold recharge." Daly (1903) more than a century ago defined 
magmatic stoping as magma emplacement due to the detachment of blocks from the roof and walls and incorporation into magma with possible reaction. Stoping itself involves the interrelated processes, including fracturing aided by preexisting foliation, bedding or fissility and thermal expansion, partial melting, and possible explosive exfoliation when stoped blocks include hydrous phases that become unstable upon heating (e.g., Beard et al. 2005). Many examples exist where geochemical and petrological evidence of digestive assimilation is strong. In one example, Barnes et al. (2004) provide evidence that up to $20 \%$ by mass of the western/annular zone of the 445 Myr old Sausfjellet pluton, Norway, was derived by mixing and imperfect hybridization of resident dioritic magma with digested stoped blocks of pelitic wallrock. Another example was demonstrated by Dickin and Exley (1981) for the Redhills epigranites, Isle of Skye, northwest Scotland, which formed by mixing of $10-30 \%$ by mass of silicic melt derived from local crust with mantlederived differentiate. Although these complex multicomponent systems cannot be described using the toy model, the principles of digestive assimilation illuminated by the toy model most likely carry over to more complex systems. Below, we summarize three R-hybridization scenarios showing the effects of composition and temperature of stoped blocks on the state of hybrid magma.

Figures $6 \mathrm{a}$ and $6 \mathrm{~b}$ illustrate the effects of cold stoped block composition on the final state of $\mathbf{H}$ magma. In these examples, initial $\mathbf{M}$ magma is $87 \%$ melt and $13 \% \alpha$ crystals by mass. For the conditions of Figure $6 \mathrm{a}$ (fraction of $\mathbf{M}$ magma equal to $\mathrm{f}_{\mathrm{o}}=$ 0.9 , stoped block is well below the solidus with a mode of $86 \%$ $\beta$ and $14 \% \alpha$ ), hybridized magma $\mathbf{H}$ is $\sim 28 \mathrm{~K}$ cooler than $\mathbf{M}$ and consists of $81 \%$ melt and $19 \% \alpha$ crystals. $\mathbf{H}$ melt is richer in component $\mathrm{B}$ relative to $\mathbf{M}$ melt $\left(X^{\mathrm{Hl}}=0.26 \mathrm{vs} . X^{\mathrm{M} 1}=0.16\right)$ reflecting the $\beta$-rich mode of the stoped block. It is noted that although in this example the stoped block is $\beta$-rich, the resulting hybridized magma remains undersaturated in $\beta$ phase. Thus, the influence of component B is seen not in the crystal population but in the composition of the melt. In Figure 6b, all values are identical to Figure 6a except now the stoped block mode is $86 \%$ $\alpha$ and $14 \% \beta$ crystals, the modal opposite of Figure $6 \mathrm{a}$. In this case, the hybridized magma temperature is only $11 \mathrm{~K}$ cooler than $T^{\mathrm{M}}$ but, at the same time, somewhat more crystal rich $(26 \% \alpha$ crystals). Note that the initial $T$ of the stoped block $\left(T_{0}^{\mathrm{R}}\right)$ is identical in these cases; differences in the $\mathbf{H}$ magma are attributed to the change from $\beta$-rich (Fig. 6a) to $\alpha$-rich (Fig. 6b) blocks being assimilated and digested. The smaller degree of cooling for the case illustrated in Figure $6 \mathrm{~b}$ is due to the smaller heat of fusion of $\beta$ crystals relative to $\alpha$ crystals showing directly how thermodynamic properties influence hybridization and postmixing magma temperature.

In Figure 7, the effect of the temperature of stoped blocks on the state of $\mathbf{H}$ magma is shown. All parameters are identical to case of Figure $6 \mathrm{~b}$ except that the pre-mixing stoped block temperature is reduced by a factor of two (from 1300 to 650 $\mathrm{K}$ ). Hybrid magma cools to $1601 \mathrm{~K}$ (cf. $1611 \mathrm{~K}$ in Fig. $6 \mathrm{~b}$ ) and the mode of $\mathbf{H}$ magma is $37 \% \alpha$ crystals vs. $26 \% \alpha$ crystals in Figure $6 \mathrm{~b}$. This result shows that when the mixing ratio is large, the temperature of the hybridized magma is a weak function of the temperature of the stoped block, whereas the mode of the stoped block is more sensitive to that temperature.
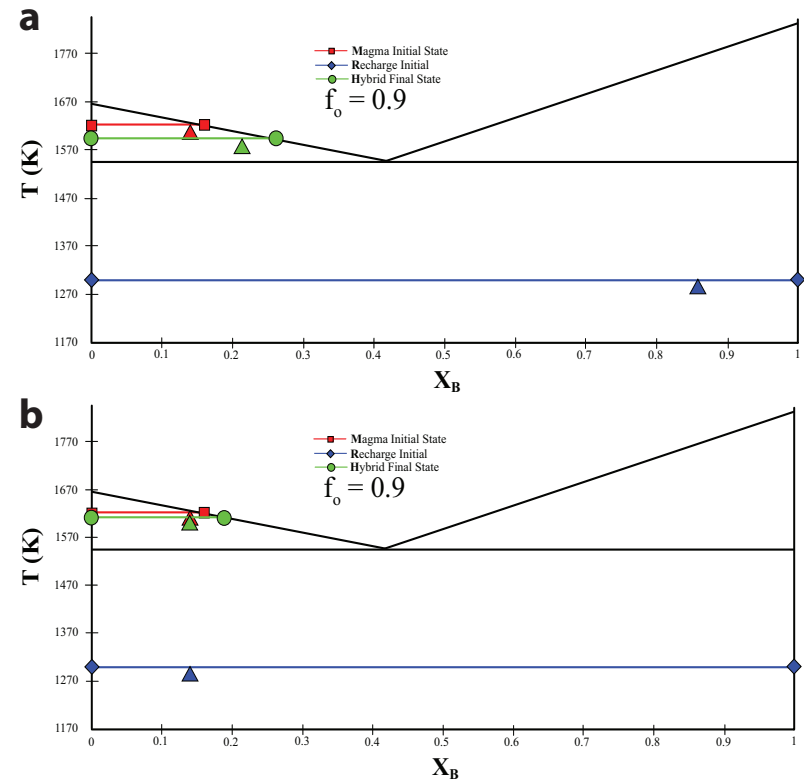

FIGURE 6. Portrayal of digestion thermodynamics of subsolidus stoped blocks $\mathbf{R}$ into $\mathbf{M}$ mush, where initial $\mathbf{M}$ magma is $87 \%$ melt and $13 \% \alpha$ crystals by mass. The fraction of $\mathbf{M}$ magma is 0.9 in the $\mathbf{M}+\mathbf{R}$ mixture. Magma (red) squares represent initial melt and solid characteristics and triangle represents bulk composition; blue diamond represents state of $\mathbf{R}$ stoped block; green circles represent $\mathbf{H}$ magma melt and solid characteristics, and green triangle represents $\mathrm{H}$ magma bulk composition. (a) The stoped block is well below the solidus with a mode of $86 \% \beta$ and $14 \% \alpha$. Hybrid magma retains no record of $\beta$ present in the stoped block. (b) Portrayal of digestion thermodynamics of subsolidus stoped blocks $\mathbf{R}$ into $\mathbf{M}$ mush $(\mathrm{L}+\alpha)$. Identical condition from a except that $\mathrm{R}$ is modally dominated by $\alpha$ instead of $\beta$. (Color online.)

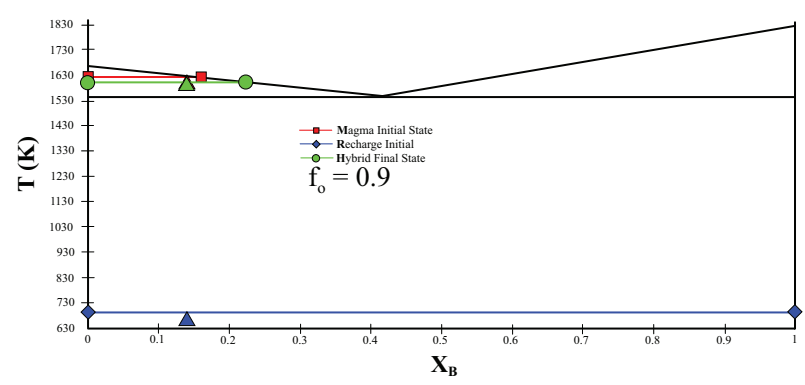

FIGURE 7. Portrayal of digestion thermodynamics of subsolidus stoped blocks $\mathbf{R}$ into $\mathbf{M}$ mush $(\mathrm{L}+\alpha)$ illustrating the effect of stoped block temperature on $\mathrm{H}$ magma outcome. Identical condition from Figure $6 \mathrm{~b}$ except that stoped block $\mathbf{R}$ is significantly cooler. (Color online.)

\section{Diabatic hybridization}

The examples presented above have been for adiabatic or R-hybridization. An alternative, diabatic hybridization (RFChybridization) is a compound recharge plus crystallization process. This is handled in the model by introduction of the parameter $\Phi$, which is the ratio of $\mathbf{H}$ magma enthalpy to the sum of the enthalpies of $\mathbf{M}$ and $\mathbf{R}$, the mixing magmas. For $\Phi$ $<1$, net heat loss occurs during the mixing process so that the 
TABLE 4. MCS calculation of R-hybridization

\begin{tabular}{|c|c|c|c|c|c|}
\hline \multirow{3}{*}{$\begin{array}{l}T\left({ }^{\circ} \mathrm{C}\right) \\
\text { Phases (modal\%) } \\
\text { Compositions (wt\%) }\end{array}$} & \multirow{2}{*}{\multicolumn{2}{|c|}{$\begin{array}{c}\mathbf{M}\left(\mathrm{f}_{\mathrm{o}}=0.53\right) \\
1180 \\
\text { Melt (55.7), } \\
\text { px (16.9), Plag (10.3), } \\
\text { Ol (7.5), Spl (9.5) }\end{array}$}} & \multirow{3}{*}{$\begin{array}{c}\mathbf{R} \\
1179.2 \\
\text { Melt + trace Ol } \\
\text { melt }^{\mathrm{R}}\end{array}$} & \multirow{2}{*}{\multicolumn{2}{|c|}{$\begin{array}{c}\mathbf{H} \\
1152.5 \\
\text { Melt (87.2), } \\
\text { Cpx (1.9), Ol (6.0), } \\
\text { Spl (5.0) } \\
\end{array}$}} \\
\hline & & & & & \\
\hline & bulk $^{\mathrm{M}}$ & melt $^{M}$ & & bulk & melt $^{H}$ \\
\hline $\mathrm{SiO}_{2}$ & 45.3 & 51.2 & 52.0 & 48.4 & 51.6 \\
\hline $\mathrm{TiO}_{2}$ & 0.9 & 1.3 & 0.6 & 0.8 & 0.8 \\
\hline $\mathrm{Al}_{2} \mathrm{O}_{3}$ & 16.4 & 16.7 & 16.5 & 16.3 & 17.1 \\
\hline $\mathrm{Fe}_{2} \mathrm{O}_{3}$ & 1.3 & 0.5 & 1.3 & 1.3 & 0.7 \\
\hline $\mathrm{Cr}_{2} \mathrm{O}_{3}$ & 2.8 & 0.05 & 0 & 1.5 & 0.07 \\
\hline $\mathrm{FeO}$ & 6.6 & 6.7 & 6.8 & 6.7 & 6.0 \\
\hline $\mathrm{MgO}$ & 11.9 & 7.2 & 7.7 & 10.0 & 7.0 \\
\hline $\mathrm{CaO}$ & 11.6 & 11.5 & 9.8 & 10.7 & 11.8 \\
\hline $\mathrm{Na}_{2} \mathrm{O}$ & 2.5 & 3.9 & 2.3 & 2.4 & 2.7 \\
\hline $\mathrm{K}_{2} \mathrm{O}$ & 0.1 & 0.2 & 0.4 & 0.2 & 0.3 \\
\hline $\mathrm{P}_{2} \mathrm{O}_{5}$ & 0.1 & 0.2 & 0 & 0.05 & 0.06 \\
\hline$\underline{\mathrm{H}_{2} \mathrm{O}}$ & 0.3 & 0.6 & 2.6 & 1.4 & 1.6 \\
\hline
\end{tabular}

hybrid magma state reflects the combined effects of adiabatic recharge and crystallization triggered by heat extraction per unit mass equal to $(1-\Phi)\left(\mathrm{h}_{\mathrm{o}}^{\mathrm{M}}+\mathrm{h}_{\mathrm{o}}^{\mathrm{R}}\right)$. This extracted heat might flow into country rock and heat or partially melt it; in the toy model, if partial melting does take place, the resulting melt is not mixed into the magma body. An example of RFC-hybridization is portrayed in Figure 8a. M magma that is saturated in $\alpha(79 \%$ melt $+21 \% \alpha)$ is hybridized with $\mathbf{R}$ magma saturated in $\beta(71 \%$ melt $+29 \% \beta)$. The diabatic parameter is set to $\Phi=0.8$. The hybrid state in this case is subsolidus, with mass fractions of $\alpha$ and $\beta$ of 0.55 and 0.44 , respectively. The heat loss in this example is sufficient to induce complete crystallization in the mixed product. This example of diabatic recharge produces a vastly different final state compared to the one portrayed in Figure 8 b, otherwise identical except that $\Phi=1$ for which the hybrid state is almost all liquid ( $98 \% \mathrm{~L}$ and $2 \% \beta$ ). These differences illustrate need for applying energy as well as mass constraints when citing "magma mixing" as a contributory cause in creating variations in bulk and phase compositions in volcanic or plutonic successions at the outcrop scale of order 1-100 m or greater. Clearly, a relatively small change of $\sim 20 \%$ in total enthalpy of the mixed system yields vastly different outcomes despite other conditions being identical.

Cessation of crystallization of a phase saturated in either $\mathbf{M}$ or $\mathbf{R}$, as illustrated in Figure $8 \mathrm{~b}$, is not an uncommon outcome in toy model diabatic or adiabatic mixing. Even for a relatively phyric $\mathbf{M}$ magma mixed with $\mathbf{R}$ at mixing ratio $\mathfrak{R}=2$ (recall $\mathfrak{R}$ $\equiv$ mass of $\mathrm{M} /$ mass of $\mathrm{R}$ ), complete resorption of $\alpha$ crystals occurs, and thus, in $\mathbf{H}$ magma, the record of such crystallization events is erased. RFC-hybridization of magmas is a possible explanation of the "pyroxene paradox" relevant to the petrogenesis of MORB (Francis 1986) that does not rely on polybaric fractionation, as significant as the latter may be. The usual resolution of the paradox is fractionation of pyroxene at depth (e.g., Bence et al. 1979; Grove and Bartels 1992; Dantas et al. 2007). This explanation draws support from observations of melt inclusions trapped in olivine phenocrysts in the absence of clinopyroxene phenocrysts that retain the fossil signature of earlier high-pressure clinopyroxene crystallization and removal. The toy model calculations show that magma mixing via the RFC-hybridization process can also cause cessation of phase precipitation under
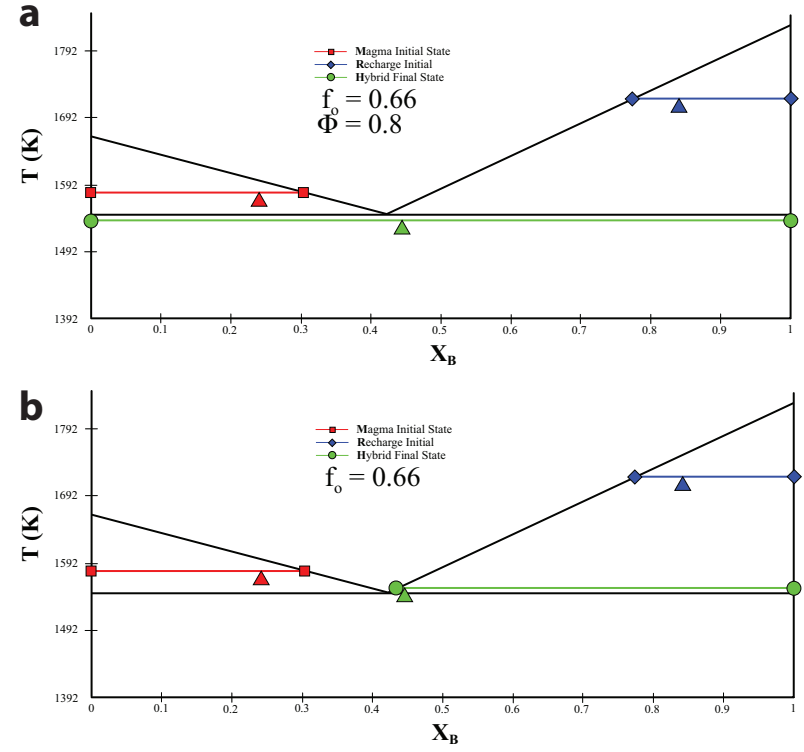

FIGURE 8. (a) Illustration of RFC-hybridization. The diabatic parameter is $\Phi=0.8$, which means that $\mathbf{H}$ magma contains $80 \%$ of the sum of the enthalpy of $\mathbf{M}$ and $\mathbf{R}$. In this case $\mathbf{H}$ magma is entirely crystalline consisting ( $45 \% \beta$ and $55 \% \alpha$ crystals). (b) Illustration of cessation of crystallization effect upon addition of recharge $\mathbf{R}$ magma to resident magma $\mathbf{M}$. In this case, $\mathbf{M}$ magma saturated in $\alpha(79 \% \mathrm{~L}+$ $21 \% \alpha$ crystals) before mixing is brought off the $\alpha$ liquidus. $\mathbf{R}$ magma is $71 \%$ melt $+29 \% \beta$ crystals. Newly formed hybrid magma is saturated in $\beta$ despite a mass-mixing ratio of $\mathbf{M}$ to $\mathbf{R}$ of 2. (Color online.)

isobaric conditions. Indeed, such a mechanism was proposed to account for the "pyroxene paradox" based on mass balance and phase equilibria arguments decades ago (O'Hara 1977; Shibata 1979; Sullivan and DeLong 1978; Rhodes et al. 1979; Walker et al. 1979). This possibility is consistent with results of the toy model, specifically RFC-hybridization under isobaric conditions. This could work in the following way: $\mathbf{M}$ magma undergoes an episode of fractional crystallization whereby melt in $\mathbf{M}$ develops the geochemical signature (major and trace elements) of $\alpha$ crystallization. If this fractional crystallization event is followed by R- or RFC-hybridization event, melt of hybrid $\mathbf{H}$, will retain the $\alpha$ crystallization signature despite its lack of $\alpha$ phenocrysts in $\mathbf{H}$. If fractional crystallization is not perfect, some crystals of $\alpha$ might be retained in $\mathbf{M}$. These would be unstable and undergo resorption during mixing and hybridization.

\section{IMPLICATIONS}

The geologic, petrologic, and geochemical record preserved in plutonic and volcanic rocks from all major petrotectonic associations is replete with evidence of magma mixing across the continuum from magma mingling to magma hybridization. Along with assimilation and fractional crystallization, magma mixing is one of the pillars upon which magmatic evolution depends. Petrologic indicators of magma mingling are typically obvious (e.g., enclaves, mingled pumice, sieve texture, partially resorbed crystals), whereas those associated with nearly hybridized magma may be "cryptic" (e.g., zoned phenocrysts) with no naked-eye heterogeneities (e.g., Dungan 1987; Humphreys et al. 2013). A 
critical issue is definition and quantification of statistical measures, such as the intensity $(I)$ and linear scale $(\Lambda)$ of segregation in light of the "scale of scrutiny" employed by the investigator. Magmas that form as the result of hybridization may go undetected. Because dynamical analysis suggests that hybridization is not uncommon the import of developing tools to identify and describe such mixed products is obvious, particularly because mantle source characteristics are often linked to those found in basaltic products. Exploratory model results presented here have implications that impact assumptions about the petrologic consequences of mixing and highlight the need to constrain opensystem petrologic models with detailed textural and chemical data and modeling using energy- and mass-constrained thermodynamic models. Among the significant implications for mixed magma systems are: (1) the relatively homogeneous bulk rock composition erupted at particular volcanoes such as Arenal (e.g., Streck et al. 2005) and Etna (e.g., Corsaro and Pompilio 2004; Armienti et al. 1984) that show clear evidence of magma mixing may be examples of the "attractor effect." Because the enthalpy interval associated with an invariant or pseudo-invariant point is relatively large, a system from which heat is being extracted (i.e., a cooling magma) would be expected to reside at or remain near this special thermodynamic state. Our hypothesis is that magmas from volcanoes such as Etna and Arenal (and others like them) can be of low-thermodynamic variance (phase rule), and thus erupted melt compositions (and whole-rock compositions in cases of low-crystallinity magmas) do not vary significantly despite evidence for complex subvolcanic magma processes revealed by texturally and compositionally complicated crystal populations (e.g., Streck et al. 2005; Andres et al. 2008; Ginibre and Davidson 2014). The concept of the attractor effect may also explain low-compositional variance in circumstances in which assimilation and fractional crystallization play key roles. (2) A commonly cited signature of magma hybridization is a heating event, as diagnosed by textural or compositional changes in minerals (e.g., Gagnevin et al. 2007; Rivera et al. 2014) and application of geothermometry (e.g., Campbell et al. 2009; Wark et al. 2007). The thermal and compositional outcomes of such mixing events are indeed captured by both the toy model and MCS and illustrate the case in which the final mixed magma temperature is higher than one of the mixing end-members. But toy and MCS results also reveal circumstances in which a mixed magma will have a temperature that is cooler than the premixing temperatures of both mixing end-members. Depending on the crystal contents of the two magmas, the temperature of the hybridized magma can be many tens of degrees cooler than either end-member; the magnitude of this effect depends on the crystal content of each mixing component as well as the fusion enthalpies of the crystals involved. An outcome of such a mixing event is mineral resorption (partial or total), and thus the question that obviously arises is how will the textural and compositional responses to these "cooling" mixing events compare and contrast with those where minerals preserve evidence of a "heating" event? That is, how would the "cooling" resorption events be differentiated from those that are a consequence of mixing events that lead to increased temperature for one mixing end-member? In cases where reliable geothermometers have been used, heating events are clear, but our results indicate that the assumption that resorption is linked to heating may not be always correct. The overriding implication is that to fully document open-system magmatic processes such as mixing (and/or assimilation) quantitative thermodynamic modeling tools must be employed. (3) Case examples presented here illustrate the intimate feedback that develops among melt composition, phase abundance, and temperature. The implication is that mixed magmas (melt +crystals) respond to mixing events in ways that cannot be predicted using a two-component melt mixing approach. The literature is replete with examples of mass-balance reconstruction using endmembers that are inferred from compositional trajectories. To a first-order, these are useful in constraining general mixing behavior, but to gain significant new insight into the consequences of magma mixing - petrologic and volcanological (i.e., catalysts to eruption) - a rigorous thermodynamic approach is necessary. While the spectrum of possible mixing outcomes for natural systems seems unmanageable, our work illustrates that through strategic toy and MCS modeling, a taxonomy of magma mixing is possible that can elucidate "families" of mixing behavior. The goal is to map these families or modes of mixing (e.g., crystalrich basalt + basalt melt; crystal rich andesite with rhyolite, etc.) into diagnostic compositional and petrologic indicators. Such a working taxonomy would provide essential information, which when combined with scale-appropriate petrologic and geochemical observations, would form the basis for documenting magma mixing that is worthy of 21 st century investigation.

\section{ACKNOWLEDGMENTS}

We thank R. Wiebe, K. Putrika, and C. Miller for useful comments on earlier versions of this work. Support from the National Science Foundation grants EAR0810127 and EAR-1427737 is gratefully acknowledged.

\section{REFERENCES CITED}

Anderson, A.T. (1976) Magma mixing: Petrological process and volcanological tool. Journal of Volcanology and Geothermal Research, 1, 3-33.

Andres, B.J., Gardner, J.E., and Housh, T.B. (2008) Repeated recharge, assimilation, and hybridization in magmas erupted from El Chichon as recorded by plagioclase and amphibole phenocrysts. Journal of Volcanology and Geothermal Research, 175, 415-426.

Appleby, S.K., Graham, C.M., Gillespie, M.R., Hinton, R.W., and Oliver, G.J.H. (2008) A cryptic record of magma mixing in diorites revealed by high-precision SIMS oxygen isotope analysis of zircons. Earth and Planetary Science Letters, 269, 105-117.

Armienti, P., Barberi, F., Innocenti, F., Pompilio, M., Romano, R., and Villari, L. (1984) Compositional variation in the 1983 and other recent Etnean lavas: Insights on the shallow feeding system. Bulletin Volcanologique, 47, 998-1007.

Bacon, C.R. (1986) Magmatic inclusions in silicic and intermediate volcanic rocks. Journal of Geophysical Research, 91, 6091-6112.

Barnes, C.G., Dumond, G., Yoshinobu, A.S., and Prestvik, T. (2004) Assimilation and crystal accumulation in a mid-crustal magma chamber; The Sausfjellet pluton, north-central Norway. Lithos, 75, 389-412.

Baxter, S., and Feely, M. (2002) Magma mixing and mingling textures in granitoids: Examples from the Galway granite, Connemara, Ireland. Mineralogy and Petrology, 76, 63-74.

Beard, J.S., Ragland, P.C., and Crawford, M.L. (2005) Reactive bulk assimilation: A model for crust-mantle mixing in silicic magmas. Geology, 33, 681-684.

Bence, A.E., Baylis, D., Bender, J.F. and Grove, T.L. (1979) Controls on the major and minor element chemistry of mid-ocean ridge basalts and glasses. Implications of Deep Drilling Results in the North Atlantic, 2nd Ewing Symposium, 331-341.

Blake, D.H., Elwell, R.W.D., Gibson, I.L., Skelhorn, R.R., and Walker, G.P.L. (1965) Some relationships resulting from the intimate association of acid and basic magmas. Quarterly Journal of the Geological Society of London, $121,31-43$

Bohrson, W.A., Spera, F.J., Ghiorso, M.S., and Creamer, J. (2014) A tool for exploring the impact of crustal contamination; the magma chamber simulator. Mineralogical Magazine, 77, 728.

Browning, P. (1984) Cryptic variation within the Cumulate Sequence of the Oman ophiolite: magma chamber depth and petrological implications. Geological 
Society of London, Special Publications, 13, 71-82.

Bunsen, R.W. (1851) Uber die processe der vulkanischen Gesteinbildungen Islands. Annotations of Physical Chemistry, 83, 197-272.

Campbell, M.E., Hanson, J.B., Minarik, W.G., and Stix, J. (2009) Thermal history of the Bandelier magmatic system; evidence for magmatic injection and recharge at $1.61 \mathrm{Ma}$ as revealed by cathodoluminescence and titanium geothermometry. Journal of Geology, 117, 469-485.

Carmichael, I.S.E., Turner, F.J., and Turner, J. (1974) Igneous Petrology. McGrawHill, New York.

Clark, S., Spera, F.J., and Yuen, D.A. (1987) Steady state double-diffusive convection in magma chambers heated from below. The Geochemical Society, Special Publication Number 1, 289-304.

Clynne, M.A. (1999) A complex magma mixing origin for rocks erupted in 1915, Lassen Peak, California. Journal of Petrology, 40, 105-132.

Coltice, N. and Schmalzl, J. (2006) Mixing times in the mantle of the early Earth derived from 2-D and 3-D numerical simulations of convection. Geophysical Research Letters, 33, L23304.

Coombs, M.L., Eichelberger, J.C., and Rutherford, M.J. (2000) Magma storage and mixing conditions for the 1953-1974 eruptions of Southwest Trident volcano, Katmai National Park, Alaska. Contributions to Mineralogy and Petrology, 140, 99-118.

Corsaro. R.A., and Pompilio, M. (2004) Magma dynamics in the shallow plumbing system of Mt. Etna as recorded by compositional variations in volcanics of recent summit activity (2000-2005). Journal of Volcanology and Geothermal Research, 137, 55-71.

Daly, R.A. (1903) The mechanics of igneous intrusion. American Journal of Science, 15, 269-298.

Danckwerts, P.V. (1953a) The definition and measurement of some characteristics of mixtures. Applied Scientific Research, A3, 279-296.

- (1953b) Theory of mixtures and mixing. Research, 6, 355-361.

Dantas, C., Ceuleneer, G., Gregoire, M., Python, M., Freydier, R., Warren, J., and Dick, H.J.B. (2007) Pyroxenites from the Southwest Indian Ridge, $9-16^{\circ} \mathrm{E}$ : Cumulates from incremental melt fractions produced at the top of a cold melting regime. Journal of Petrology, 48, 647-660.

Davaille, A. (1999a) Two-layer thermal convection in miscible viscous fluids. Journal of Fluid Mechanics, 379, 223-253.

- (1999b) Simultaneous generation of hotspots and superswells by convection in a heterogeneous planetary mantle. Nature, 402, 756-760.

DePaolo, D.J. (1985) Isotopic studies of processes in mafic magma chambers: I. The Kigapait Intrusion, Labrador. Journal of Petrology, 26, 925-951.

Dickin, A.P., and Exley, R.A. (1981) Isotopic and geochemical evidence for magma mixing in the petrogeneis of the coire uaigneich granophyre, Isle of Skye, N.W. Scotland. Contributions to Mineralogy and Petrology, 76, 98-108.

Didier, J., and Barbarin, B. (1991) Enclaves and granite petrology. Developments in Petrology, 13

Dungan, M.A. (1987) Open system magmatic evolution of the Taos Plateau Volcanic Field, norhtern New Mexico: II the genesis of cryptic hybrids. Journal of Petrology, 28, 955-977.

Dunham, A.C., and Wadsworth, W.J. (1978) Cryptic variation in the Rhum layered intrusion. Mineralogical Magazine, 42, 347-356.

Dyson, F.J. (2000) Gravity is cool; or, why our universe is hospitable to life. Origins of Life and Evolution of the Biosphere, 30, 115.

Eales, H.V. (2002) Caveats in defining the magmas parental to the mafic rocks of the Bushveld Complex, and the manner of their emplacement; review and commentary. Mineralogical Magazine, 66, 815-832.

Eichelberger, J.C. (1980) Vesiculation of mafic magma during replenishment of silicic magma reservoirs. Nature, 288, 446-450.

Eichelberger, J.C., Chertkoff, D.G., Dreher, S.T., and Nye, C.J. (2013) Magmas in collision: rethinking chemical zonation in silicic magmas. Geology, 28, 603-606.

Farnetani, C.Z., and Samuel, H. (2003) Lagrangian structures and stirring in the Earth's mantle. Earth and Planetary Science Letters, 206, 335-348.

Francis, D. (1986) The pyroxene paradox in MORB glasses-A signature of picritic parental magmas? Letters to Nature, 319, 586-589.

Furman, T., and Spera, F.J. (1985) Commingling of acid and basic magma and implications for the origin of I-type xenoliths, I Field and petrochemical relations of an unusual dike complex at Eagle Lake, Sequoia National Park, Sierra Nevada, California, U.S.A. Journal of Volcanology and Geothermal Research, 24, 151-178.

Gagnevin, D., Waight, T.E., Daly, S.T., Poli, G., and Conticelli, S. (2007) Insights into magmatic evolution and recharge history in Capraia Volcano (Italy) from chemical and isotopic zoning in plagioclase phenocrysts. Journal of Volcanology and Geothermal Research, 168, 28-54.

Gibson, D., Lux, D.R., and Choate, M.A. (2003) Petrography of a "cryptic" mixed magma system-The Mount Waldo granite, coastal Maine. Atlantic Geology, 39, DOI: http://dx.doi.org/10.4138/1178.

Ginibre, C., and Davidson, J.P. (2014) Sr isotope zoning in plagioclase from Parinacota Volcano (northern Chile): Quantifying magma mixing and crustal contamination. Journal of Petrology 55, 1203-1238.
Gonnermann, H.M., Manga, M., and Jellinek, A.M. (2002) Dynamics and longevity of an initially stratified mantle. Geophysical Research Letters, 29, 1399.

Grove, T.L., and Bartels, K.S. (1992) The relation between diogenite cumulates and eucrite magmas. Proceedings of the Lunar and Planetary Science Conference, 22, 437-445.

Gurnis, M., and Davies, G.F. (1986) The effect of depth-dependent viscosity on convective mixing in the mantle and the possible survival of primitive mantle. Geophysical Research Letters, 13, 541-544.

Haller, G. (2001) Distinguished material surfaces and coherent structures in threedimensional fluid flows. Physica D, 149, 248-277.

Hibbard, M.J. (1981) The magma mixing origin of mantled feldspars. Contributions to Mineralogy and Petrology, 76, 158-170.

(1991) Textural anatomy of twelve magma-mixed granitoid systems. In J. Didier and B. Barbarin, Eds., Enclaves and Granite Petrology, Developments in Petrology, 13, p. 431-443. Elsevier, Amsterdam.

Humphreys, M.C.S., Edmonds, M., Plail, M., Barclay, J., Parkes, D., and Christopher, T. (2013) A new method to quantify the real supply of mafic components to a hybrid andesite. Contributions to Mineral Petrology, 165, 191-215.

Huppert, H.E., Sparks, R.S.J., and Turner, J.S. (1982) Effects of volatiles on mixing in calc-alkaline magma systems. Nature, 297, 554-557.

Irvine, T.N. (1970) Heat transfer during solidification of layered intrusions; I, sheets and sills. Canadian Journal of Earth Sciences, 7, 1031-1061.

Jellinek, A.M., and Kerr, R.C. (1999) Mixing and compositional stratification produced by natural convection; 2 applications to the differentiation of basaltic and silicic magma chambers and komatiite lava flows. Journal of Geophysical Research, 104, 7203-7218.

Kamber, B.S., and Collerson, K.D. (2000) $\mathrm{Zr} / \mathrm{Nb}$ systematics of ocean island basalts reassessed - Case for binary mixing. Journal of Petrology, 41, 1007-1021.

Kellogg, L.H., and Turcotte, D.L. (1990) Mixing and the distribution of heterogeneities in a chaotically convecting mantle. Journal of Geophysical Research, 95, 421-432.

Koh, T.Y., and Legras, B. (2002) Hyperbolic lines and the stratospheric polar vortex. Chaos, 12, 382-394.

Landi, P., Metrich, N., Bertagnini, A., and Rosi, M. (2004) Dynamics of magma mixing and degassing recorded in plagioclase at Stromboli (Aeolian Archipelago, Italy). Contributions to Mineralogy and Petrology, 147, 213-227.

Langmuir, C.H. (1989) Geochemical consequences of in situ crystallization. Nature (London), 340, 199-205.

Larson, L., Thomas, C., Eppinga, M., and Coulthard, T. (2014) Exploratory modelling: Extracting causality from complexity. Eos, 95, 285-292.

Le Bars, M., and Davaille, A. (2002) Stability of thermal convection in two superimposed miscible viscous fluids. Journal of Fluid Mechanics, 471, 339-363. (2004a) Large interface deformation in two-layer thermal convection of miscible viscous fluids. Journal of Fluid Mechanics, 499, 77-110.

- (2004b) Whole-layer convection in an hetergeneous planetary mantle. Journal of Geophysical Research, 109, B03403.

Lesher, C.E., and Spera, F.J. (2015) Thermodynamic and transport properties of silicate melts and magma. In H. Sigurdsson, B. Houghton, H. Rymer, J. Stix, and S. McNutt, Eds., The Encyclopedia of Volcanoes, 113-141. Academic Press, Elsevier, Amsterdam.

Liu, M., Muzzio, F.J., and Peskin, R.L. (1994) Quantification of mixing in aperiodic chaotic flows. Chaos, Solutions and Fractals, 4, 869-893.

McCallum, I.S., Raedeke, L.D., and Mathez, E.A. (1980) Investigations of the Stillwater complex; part I, stratigraphy and structure of the banded zone. American Journal of Science, 280-A, Part 1, 59-87.

Morse, S.A. (2008) Compositional convection trumps silicate liquid immiscibility in layered intrusions: A discussion of "liquid immiscibility and the evolution of basaltic magma" by Veksler et al., Journal of Petrology 48, 2187-2210. Journal of Petrology, 49, 2157-2168.

Nakamura, M. (1995) Continuous mixing of crystal mush and replenished magma in the ongoing Unzen eruption. Geology (Boulder), 23, 807-810.

O'Hara, M.J. (1977) Geochemical evolution during fractional crystallization of a periodically refilled magma chamber. Nature (London), 266, 503-507.

Oldenburg, C.M., Spera, F.J., Yuen, D.A., and Sewell, G.H. (1989) Dynamic mixing in magma bodies; Theory, simulations, and implications. Journal of Geophysical Research, 94, 9215-9236.

Olson, P., Yuen, D.A., and Balsiger, D. (1984) Mixing of passive heterogeneities by mantle convection. Journal of Geophysical Research, 89, 425-436.

Ottino, J.M. (1989) The Kinematics of Mixing: Stretching, Chaos and Transport. Cambridge University Press, U.K.

Pabst, A. (1928) Observations on inclusions in the granitic rocks of the Sierra Nevada. University of California Publications, 17, 325-386.

Poje, A.C., and Haller, G. (1999) Geometry of cross-stream mixing in a double-gyre ocean model. Journal of Physical Oceanography, 29, 1649-1665.

Petrelli, M., Perugini, D., and Poli, G. (2006) Time-scales of hybridisation of magmatic enclaves in regular and chaotic flow fields: Petrologic and volcanologic implications. Bulletin of Volcanology, 68, 285-293.

(2011) Transition to chaos and implications for time-scales of magma hybridization during mixing processes in magma chambers. Lithos, 125, 211-220. 
Reid, J.B., Evans, O.C., and Fates, D.G. (1983) Magma mixing in granitic rocks of the central Sierra Nevada, California. Earth and Planetary Science Letters, $66,243-261$.

Rivera, M., Thouret, J.C., Samamiego, P., and Le Pennec, J.L. (2014) The 2006-2009 activity of the Ubinas Volcano (Peru): Petrology of the 2006 eruptive products and insights into genesis of andesite magmas, magma recharge and plumbing system. Journal of Volcanology and Geothermal Research, $270,122-141$

Rhodes, J.M., Dungan, M.A., Blanchard, D.P., and Long, P.E. (1979) Magma mixing at mid-ocean ridges: Evidence from basalts drilled near $22^{\circ} \mathrm{N}$ on the Mid-Atlantic Ridge. Tectonophysics, 55, 35-61.

Sakuyama, M. (1984) Magma mixing and magma plumbing systems in island arcs. Bulletin Volcanologique, 47, 685-703.

Salisbury, M.J., Bohrson, W.A., Clynne, M., Ramos, F.C., and Hoskin, P. (2008) Origin of the 1915 Lassen Peak eruption by magma mixing: Evidence for formation of chemically distinct plagioclase populations from crystal size distribution and in situ chemical data. Journal of Petrology, 49, 1755-1780.

Shibata, T. (1979) Pigeonite-bearing basalts dredged from the Puerto Rico trench: A microprobe study. Marine Geology, 30, 285-297.

Smith, R.L. (1979) Ash-flow magmatism. Special Papers, Geological Society of America, 180, 5-28.

Sparks, R.S.J., Sigurdsson, H., and Wilson, L. (1977) Magma mixing: A mechanism for triggering acid explosive eruptions. Nature, 267, 315-318.

Spera, F.J. (1992) Lunar magma transport phenomena. Geochimica et Cosmochimica Acta 56, 2253-2265.

(2000) Physical properties of magma. In H. Sigurdsson, Ed., Encyclopedia of Volcanoes, p. 71. Academic Press, San Diego.

Stelten, M.E., Cooper, K.M., Vasquez, J.A., Reid, M.R., Barfod, G.H., Wimpenny, J., and Yin, Q. (2013) Magma mixing and the generation of isotopically juvenile silicic magma at Yellowstone caldera inferred from coupling ${ }^{238} \mathrm{U}-{ }^{230} \mathrm{Th}$ ages with trace elements and $\mathrm{Hf}$ isotopes in zircon and $\mathrm{Pb}$ isotopes in sanidine. Contributions to Mineral Petrology, 166, 587-613.

Streck, M.J., Dungan, M.A., Bussy, F., and Malavassi, E. (2005) Mineral inventory of continuously erupting basaltic andesites at Arenal volcano, Cost Rica: implications for interpreting monotonous crystal-rich mafic arc stratigraphies. Journal of Volcanology and Geothermal Research 140, 133-155.

Sugawara, T., and Akaogi, M. (2003) Heats of mixing of silicate liquid in the systems diopside-anorthite-akermanite, diopside-anorthite-forsterite, and diopside-silica. American Mineralogist, 88, 1020-1024.

Sullivan, J.W., and DeLong, S.E. (1978) Major element geochemistry of north arm Mt. Gabbros, Bay of Islands Ophiolite Complex, Newfoundland. Abstracts with Programs Geological Society of America, 10, 87.

Tackley, P.J. (2007) Mantle Geochemical Geodynamics. In D. Bercovici and G.
Schubert, Eds., Treatise on Geophysics, Mantle Dynamics, 7, p. 437-505. Elsevier, Amsterdam.

Tepley, F.J. III, Davidson, J.P., Tilling, R.I., and Arth, J.G. (2000) Magma mixing. recharge and eruption histories recorded in plagioclase from El Chichon Volcano, Mexico. Journal of Petrology, 41, 1397-1411.

Tisza, L. (1977) Generalized Thermodynamics, pp. 384. The MIT Press, Cambridge. Todesco, M., and Spera, F.J. (1992) Stability of a chemically layered upper mantle. Physics of the Earth and Planetary Interiors, 71, 85-95.

Troll, V.R., and Schmincke, H.U. (2002) Magma mixing and crustal recycling recorded in ternary feldspar from compositionally zoned peralkaline ignimbrite "A," Gran Canaria, Canary Islands. Journal of Petrology, 43, 243-270.

van Keken, P.E., Ballentine, C.J., and Hauri, E.H. (2003) Convective mixing in the Earth's mantle. In R.W. Carlson, Ed., Treatise on Geochemistry, p. 471-491. Elsevier, Amsterdam.

Vantongeren, J.A., and Mathez, E.A. (2013) Incoming magma composition and style of recharge below the pyroxenite marker, eastern Bushveld complex, South Africa. Journal of Petrology, 54, 1585-1605.

Voth, G.A., Haller, G.H., and Gollub, J.P. (2002) Experimental measurements of stretching fields in fluid mixing. Physical Review Letters, 88, 254501.

Wager, L.R., and Brown, G.M. (1968) Layered Igneous Rocks. Oliver and Boyd, London.

Walker, D., Shibata, T., and DeLong, S. (1979). Abyssal tholeiites from the Oceanographer Fracture Zone. Contributions to Mineral Petrolology, 70, 111-125.

Wark, D.A., Hildreth, W., Spear, F.S., Cherniak, D.J., and Watson, E.B. (2007) Pre-eruption recharge of the Bishop magma system. Geology 35, 235-238.

Wiebe, R.A. (1973) Relations between coexisting basaltic and granitic magmas in a composite dike. American Journal of Science, 273, 130-151.

(1987) Rupture and inflation of a basic magma chamber by silicic liquid. Nature, 326, 69-71.

(1996) Mafic-silicic layered intrusions: The role of basaltic injections on magmatic processes and the evolution of silicic magma chambers. Geological Society of America Special Paper, 315, 233-242.

Wiebe, R.A., and Hawkins, D. (2015) Growth and impact of a mafic-silicic layered intrusion in the Vinalhaven Intrusive Complex, Maine. Journal of Petrology, 56, 273-298.

Wilcox, R.E. (1999) The idea of magma mixing: History of a struggle for acceptance. The Journal of Geology, 107, 421-432.

MANUSCRIPT RECEIVED JANUARY 15, 2015

MANUSCRIPT ACCEPTED OCTOBER 27, 2015

MANUSCRIPT HANDLED BY CALVIN MILLER 